NBSIR 84-2980

\title{
Research Priorities for Improving the Effectiveness of Active Solar Hot Water and Space Conditioning Systems
}

Robert D. Dikkers

U.S. DEPARTMENT OF COMMERCE

National Bureau of Standards

National Engineering Laboratory

Center for Building Technology

Gaithersburg, Maryland 20899

William J. Kennish

TPI, Inc.

Beltsville, Maryland 20705

C. Byron Winn

William Huston

Solar Environmental Engineering Company, Inc.

Ft. Collins, Colorado 80524

December 1984

Prepared for

U.S. Department of Energy

nffice of Solar Heat Technologies tive Heating and Cooling Division Ishington, DC 20585 

"1,

RESEARCH PRIORITIES FOR IMPROVING THE

EFFECTIVENESS OF ACTIVE SOLAR HOT

WATER AND SPACE CONDITIONING

SYSTEMS

Robert D. Dikkers

U.S. DEPARTMENT OF COMMERCE

National Bureau of Standards

National Engineering Laboratory

Center for Building Technology

Gaithersburg, Maryland 20899

William J. Kennish

TPI, Inc.

Beltsville, Maryland 20705

C. Byron Winn

William Huston

Solar Environmental Engineering Company, Inc.

Ft. Collins, Colorado 80524

December 1984

Prepared for

U.S. Department of Energy

Office of Solar Heat Technologies

Active Heating and Cooling Division

Washington, DC 20585

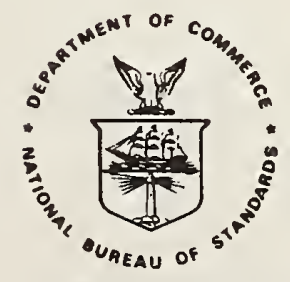

U.S. DEPARTMENT OF COMMERCE, Malcolm Baldrige, Secretary

NATIONAL BUREAU OF STANDARDS, Ernest Ambler, Director 
The authors gratefully acknowledge the cooperation and contributions of the various members of the solar industry (manufacturers, designers, contractors, researchers) who participated in the two meetings held in August 1983. The preparation of a draft report on research issues for advanced systems (basis for Section 3 of this report) by Charles Kutscher, Solar Energy Research Institute (SERI), is also appreciated. The support and comments of Morris Skalka and Robert Hassett, Active Solar Heating and Cooling Division, Department of Energy (DOE), and the assistance of Larry Salamone and Karen Lister, National Bureau of Standards (NBS), in the planning and conduct of the August 1983 meetings are also gratefully acknowledged.

The following individuals provided useful review comments on a previous draft (February 1984) of this report: William Schertz, Argonne National Laboratory: Morris Skalka, DOE; Paul Pekrul and William Marlatt, ETEC/Rockwell International; Freeman Ford, FAFCO; Robert Aasen, Honeywell; John Avery, Los Almos National Laboratory; Joseph Greenberg and Thomas Faison, NBS; and Charles Rutscher, SERI. 
1.1 Background................................. I

1.2 Scope.................................... I

1.3 Meeting Participants......................... 3

1.4 Meeting Organization and Methodologies........... 5

Section 2. RESEARCH RBCOMMENDATIONS FOR STATE-OF-THE-ART ACTIVE SOLAR ENERGY SYSTEMS.......................... 5

2.1 Introduction.............................. 5

2.2 General Meeting Recommendations

(August $2-3,1983) \ldots \ldots \ldots \ldots \ldots \ldots \ldots \ldots \ldots . \ldots . \ldots$

2.3 Control Subsystem Meeting Recommendations

(Augut 9-10, 1983) ............................ 12

Section 3. RESEARCH RECOMMENDATIONS FOR ADVANCED ACIIVE

SOLAR ENERGY SYSTEMS........................... 17

3.1 Residential Direct Heating and Hot Water-Liquid... 18

3.2 Residential Direct Heating and Hot Water-Air...... 19

3.3 Residential Open Cycle solid Desiccant Cooling, Heating, DHW........................ 19

3.4 Commercial Solid Desiccant/Vapor Compression....... 19

3.5 Commercial Absorption Cooling.................. 20

3.6 Commercial Rankine Power Generation and cooling... 20

3.7 Ground Coupled Solar Assisted Heat Pump Community Beating.......................... 20

Section 4.

4.1 State-of-the Art Systens.................... 21

4.2 Advanced Systens........................... 22

Section 5. REFERENCES................................ 22

APPENDIX A. Development of a prioritization methodology for the system effectiveness research program at the U.S. Department of Energy................... 23

APPENDIX B. Solar heating and cooling control subsystems......... 31 



\subsection{Background}

In 1980, a Department of Energy (DOE) program plan was developed to address the reliability and maintainability (R\&M) of active solar energy systems [1]*. The goal of this R\&M program was to "accelerate the removal of reliability and maintainability as major concerns impeding the widespread adoption of solar energy systems." Primary objectives of the program were to:

- Provide all groups that have solar R\&M concems with the information that is available to the program and that is necessary to alleviate those concerns.

- Assist the solar energy industry in improving levels of R\&M performance in state-of-the-art solar energy systems, components, and materials.

Assist in the early development of a viable infrastructure for the design, manufacture, installation, and maintenance of reliable, maintainable, and durable solar energy systems.

Assist in the development of appropriate standards, code provisions, and certification programs relating to the R\&M performance of solar energy systems, components, and materials.

Develop the information required to support the other activities within the R\&M program.

In addition to reliability and maintainability, the 1980 program plan [1] recognized that other factors such as thermal performance, cost and site constraints were also important components of "system effectiveness" (Fig. 1). In order to maximize system effectiveness, the designer or manufacturer must often consider tradeoffs between these various factors.

\subsection{Scope}

In 1983, the DOE Active Solar R\&M program was renamed the "Systems Effectiveness Research" (SER) program. The objective of the program was to identify, assess and initiate research into those factors which influence the effectiveness of solar space conditioning systems. As part of the FY 1983 SER program coordinated by the Solar Energy Research Institute (SERT), the National Bureau of Standards (NBS) was assigned responsibility for developing research priorities for improving the effectiveness of active solar hot water and space conditioning systems. To carry out this responsibility, NBS in cooperation with various industry representatives, organized and conducted two meetings in August 1983. With support from TPI, Inc., the first meeting was held at NBS on August 2-3, 1983 and covered all major aspects of state-of-the-art active solar ht water and space conditioning systems. The second meeting dealt only with solar

‡ Numbers in bracket refer to references listed in section 5. 


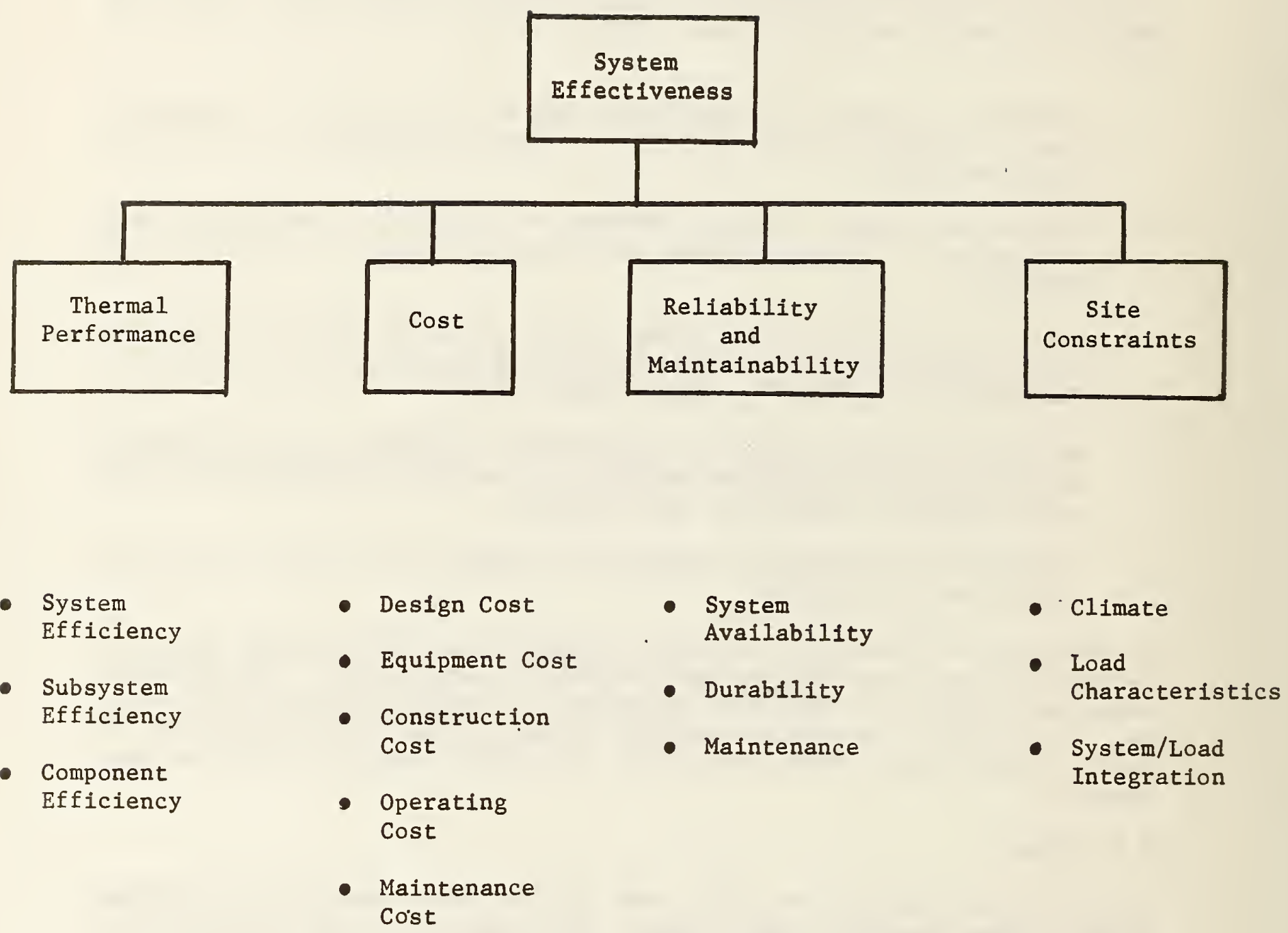

Figure 1: Components of System Effectiveness 
control subsystems and was held at NBS on August 9-10, 1983. Support for this meeting was provided by the Solar Environmental Engineering Company, Inc.. Recommendations obtained in these meetings are presented and discussed in section 2. Recommended research priorities for addressing the effectiveness of advanced active solar systems (not dealt with at August 1983 meetings) are presented in section 3. A summary of recommended research priorities for improving the effectiveness of state-of-the-art and advanced active solar systems is provided in Section 4.

\subsection{Meeting Participants}

Solar industry representatives (manufacturers, contractors, architects, engineers) who participated in the ranking of recommended research areas at the August 2-3, 1983 were:
- Donald Bowden Huntsville, Alabama
Solar Unlimited, Inc.
- Andrew Parker
Mueller Associates, Inc. Baltimore, Maryland
- Eaward Butler
Sunrise Solar Services., Inc.
- Richard Rittleman
Suffield, Connecticut
Burt Hill Rosar Rittleman
Associates
Butler, Pennsylvania
- Brad Davis
Marc Energy Corporation
Cinnaminson, New Jersey
- Robert Spears
Reynolds Metals Company
- Webb Farber
U.S. Solar Corporation
Hampton, Florida
Richmond, Virgin
- Joseph Frissora
Sunnaster Corporation
Corning, New York
- Burt swerdling
Grumman Energy Systems, Inc.
Melville, New York
- Susumu Raraki
Colorado State University
Ft. Collins, Colorado
- Raymond Yaeger
Symergic Resources corporation
Bala Cynwyd, Pennsylvania

Government and government contractor staff participating in this meeting included:

- John Avery

Los Almos National Laboratory

Los Almos, New Mexico

- Robert Dikkers

National Bureau of standards

Gaithersburg, Maryland

- Ed Gray

JRB Associates

McLean, Virginia
- Chuck Rutscher

Solar Energy Research Inst.

Golden, Colorado

- Terry Logee

Vitro Laboratories

Silver Spring, Maryland

- William Schertz

Argonne National Laboratory

Argonne, Illinois 
- Robert Hassett

Department of Energy

Washington, DC

- Oscar Hillig

ETEC/Rockwell International

Canoga Park, Califomia
- Morris Skalka

Department of Engery

Washington, DC

- Dave Waksman

National Bureau of Standards

Gaithersburg, Maryland

- William Kennish

TPI, Inc.

Beltsville, Maryland

The following persons (controls manufacturers, govemment staff, etc.) took part in the August 9-10, 1983 meeting:

- Bob Aasen

Honeywell/TSC

Roseville, Minnesota

- Rick Boers

Dynatech Energy Controls

Lakewood, Colorado

- Cliff Carwile

Department of Energy

Washington, DC

- Gibb Conover

Independent Energy Inc.

East Greenwich, Rhode Island

- Robert Dikkers

National Bureau of Standards

Gaithersburg, Maryland

- Hunter Fanney

National Bureau of Standards

Gaithersburg, Maryland

- Robert Hassett

Department of Energy

Washington, DC

- Peter Herczfeld

Drexel University

Philadelphia, Pennsylvania

- Bill Huston

Solar Environmental Engr. Co.

Fort Collins, Colorado

- Peter Jacobs

Novan Energy, Inc.

Boulder, Colorado
- Joseph Mibelli

Rho Sigma, Div. of Watsco

Hialeah, Florida

- Dennis Miller

Johnson Controls

Milwaukee, Wisconsin

- Daryl Myers

Solar Energy Research Inst. Colden, Colorado

- David Parks

Hellotrope Ceneral

Spring Valley, California

- Paul J. Pekrul

Rockwell International/ETEC

Canoga Park, Califormia

- Kent Reed

National Bureau of Standards

Gaithersburg, Maryland

- Shari Rossi

Vitro Laboratories

Silver Spring, Maryland

- Morris Skalka

Department of Energy

Washington, DC

- C. Byron Winn

Solar Environmental Eng. Co. Fort Collins, Colorado 
Approximately one month prior to the August 2-3, 1983 meeting, various background information was sent to the invited meeting participants. This information package included a discussion of system effectiveness, a listing of proposed research areas, and a proposed methodology for prioritizing research areas. Detailed information on the proposed prioritization methodology and the methodology which was used at the August 2-3, 1983 meeting is discussed in Appendix A.

Similarly, prior to the August 9-10, 1983 meeting, a background paper on solar heating and cooling control subsystems was prepared and distributed to the invited participants. This paper (Appendix B) contained a review of control theory, a literature review and recommended research areas. The prioritization methodology used at the earlier meeting was not employed at the August 9-10, 1983 meeting. Instead, recommended solar control research activities were developed on the basis of individual presentations and working group discussions.

2. RESEARCH RECOMMENDATIONS FOR STATE-OF-THE-ART ACTIVE SOLAR ENERGY SYSTEMS

\subsection{Introduction}

The purpose of this section is to present recommended research priorities for improving the effectiveness of state-of-the-art active solar energy systems which were developed at the two meetings held in August 1983. Section 2.2 presents the recammendations from the general meeting held on August 2-3 and Section 2.3 discusses the recommendations from meeting held on August 9-10 which focused on solar control subsystems.

\subsection{General Meeting Recommendations (August 2-3, 1983)}

Eighteen proposed research areas which were considered and ranked are listed in Table 1. The prioritized list of research areas as developed by the industry participants is shown in Table 2. Out of the eighteen research areas evaluated, the top three ranked areas were: (1) installer training; (2) designer training; and (3) packaging and installation methods. As shown, industry participants believed these important areas contribute to systems effectiveness and should be addressed by the solar community. Energy distribution was the only other area which federal government support was deemed to be inappropriate or not needed. A brief summary of the key points relating to each research area is presented in the following paragraphs.

Installer Training. The training of competent installers has been a major problem in the past. Poor or incorrect installation of various subsystems, such as controls, has accounted for a significant loss in performance and system failure. Improvement in this area has considerable potential for enhancing field performance and a relatively high probability of success. The cost is relatively small and the time for its effect to be felt upon the industry should be quick. Although this area ranks as the top priority, most major manufacturers train their own distributors and do not feel that this is an area where DOE could contribute significantly. 
Table 1. List of Proposed Research Areas

(Not prioritized)

1. Absorber Development

- Selective Surface Materials - Plate Design

2. Glazing Development

- Thir Film

- Degradation of Polymers

- Reduction of Themal Losses

- Durability Under Impact

- Anti-Reflective coatings

3. Controls

- Control Strategy Development

- Variable speed Pumps \& Fans

- Reliability

- Calibration Techniques

- Sensors

- Standardized strategies

- Small Programmable Controllers

- Monitors

4. Storage

- Liners

- Stratification Methods

- Phase Change

- Tank Durability

- Annual Cycle

- Systen Iosses

5. Machines

- Absorption Chiller Development - Rankine Development

- Desiccant System Development - Heat Pumps

6. Energy Distribution

- Heat Exchangers

- Piping - Leakage

- Parasitics - Pumps/Fans

- Low Cost Piping

- Flexible Coupling, Sealants, Expansion

7. Heat Transfer Fluids

- Freeze Protection

- Air Vapor Blockage

- Flow Balancing

- Ducts - Leakage

- Low Cost Ducting

- High Quality/Low cost Air Flow Controllers

- Corrosion

- Refrigerants

8. Systems Performance

- Hot Water

- Cooling

- Side by Side Comparisons

- Heating

- Field Data Acquisition

- Load Profile

9. Modeling and Simulation

- Components

- Systems

10. Design Tools

11. Test and Evaluation Procedures

- Materials

- Systems

- Components 
Table 1. List of Proposed Research Areas (CONIINUED) (Not prioritized)

12. Designer Training Programs

13. Packaging and Installation Methods

14. Installer Training Programs

15. Consumer Awareness Programs

16. Insulation

- Collector

- Storage

- Piping

17. Technology Transfer

18. Mirror Reflectivity/Durability 
Table 2. Industry Ranking of Systems Effectiveness Research Areas

Research Area

1. Installer Training

2. Designer Training

3. Packaging and Installation Methods

4. Controls

5. Insulation

6. Design Tools

7. Systems Performance

8. Technology Transfer

9. Energy Distribution

10. Absorber Development

11. Storage

12. Modeling and Simulation

13. Test and Evaluation Procedures

14. Consumer Awareness

15. Heat Transfer Fluids

16. Mirror Reflectivity and Durability

17. Glazing Development

18. Machines
Federal

Overall Weighted Score*

161.1

157.1

155.0

154.3

150.1

150.0

148.4

145.2

143.8

140.9

140.2

137.3

135.5

132.2

128.9

126.8

114.9

94.0
Government

Support

Agpropriate

No

No

No

Yes

Yes

Yes

Yes

Yes

No

Yes

Yes

Yes

Yes

Yes

Yes

Yes

Yes

Yes

* See Appendix A for the methodology used in developing these weighted scores. 
Designer Training. Another major contributor to poor performance of installed systems has been the lack of experience or training of the designers of the system. Often the projects were first efforts for the designer and therefore mistakes were made. Although this applies primarily to larger systems where a designer is more heavily involved, it has also been experienced in smaller residential systems.

Industry has overcome much of the problem in residential applications by going more toward packaged systems. Even space heating systems are becoming more packaged. Commercial systems will continue to be a problem as long as the number of jobs is few. Design courses are available throughout the country but are not attended because of the lack of market pressure. There is not any significant role for DOE to play in the training of designers although the development of design tools and other technical resource material for designers is appropriate as discussed later. The solar community can assist when the need forces designers to solicit help.

Packaging and Installation Methods. Instal lation has been problem in active solar applications since the industry first began to develop. The need to piece together complicated systems and the lack of trained installers has resulted in many poorly functioning or non-functioning systems in the field. In response to this problem, manufacturers have gone to packaged designs and simple installation methods. This has been most successful on small systems (domestic hot water and small space heating) where close control over the product distribution network is exercised by the manufacturer. This is an area which must be addressed by any solar company that expects to be successful but does not require support from DOE.

Controls. The control subsystem of a solar system include those active and passive elements which govern the operation of the system. Sensors, controllers, actuators, dampers, vents, drain valves, etc. are ali components of the controls subsystem Virtually all of these components have experienced problems in the past.

Sensors have had one major problem which is yet to be resolved--sensor drift. The output of a sensor is not necessarily stable over time. Therefore, measurements, and especially differential temperature measurements, become inaccurate and result in improper system operation. The lack of a reliable and accurate low flow, non restricting flow meter has been a problem primarily for measuring system performance but this does not currently play a significant role in most control systems. This may change as more sophisticated variable flow control strategies are developed in the future.

The controller itself has had failure problems due to manufacturing and environment problems but these problems seem to be disappearing as experience is gained. Better units are now available with much better reliability. Back dampers, vents and other control devices have caused problems but these are also being solved through the natural evolution of the industry.

DOE could provide support in two major areas. First, recommended test methods and evaluation procedures which would aid industry in developing reliable controllers and sensors should be prepared. In this regard, other 
agencies should be surveyed for related research. Second, DOE should investigate the use of advanced control strategies to determine if substantial gains in overall HVAC and solar system performance could be realized. This will include the use of variable collector flow to preserve storage stratification, use of offpeak rates, and in general overall system optimization. This work will probably not be pursued by industry. (Note: Additional detailed research recommendations on solar control subsystems are also presented in Section 2.3.)

Insulation. The long term integrity of insulating materials used in solar systern, especially those exposed to higher temperatures, needs to be determined and probably improved. However, this offers little potential for cost reduction or performance improvement. If the demand is sufficient, industry will carry out this role. Other technology activities should be monitored by DOE to identify insulation advances. In addition, compilation and dissemination of available information on recommended insulation materials and installation practices for various applications (collectors, piping, thermal storage) would be helpful to the solar industry.

Design Tools. Many of the installed systens in the field today are poorly designed. Poor collector area/storage volume ratios, pump sizes, HVAC interface requirements, etc. have all led to inefficient operation. Because of the trend toward packaged systems, much of the need for this type of information has been alleviated. However, for field assembled systems there still remains a need for better design guidelines.

With respect to sizing and performance analysis many companies develop and disseminate design tools. DOE's most appropriate role should be the validation of these design tools, which has not been completely accomplished to date.

Systems Performance. Although system performance testing of advanced concepts is extremely important, the monitoring of field systems seems to be relatively non-productive. Not only are the monitoring programs extremely expensive but the results have been of little use by practitioners in improving cost or performance. Even when system performance data is reported, the uncertainty and format of the data render it virtually useless. In future field monitoring programs, more emphasis should be placed on the performance of components and subsystems so that manufacturers can determine those areas which work well. The possibility

of a manufacturer replicating a system configuration exactly as well as the environmental conditions under which it operated are almost nonexistant and therefore the overall system data are not as important as component or subsystem data.

System and component testing should support the design tool development and validation efforts, test and evaluation procedure development activity, and modeling and simulation work. System testing should not, however, generate performance data only for the sake of creating the data but should be more strongly driven by the other research activities. DOE should support this work, as needed since industry is not typically in a position to do so.

Technology Transfer. As noted in other areas previously discussed, adequate information may exist but is not being successfully disseminated 
to potential users. This, in general, is the case in active solar energy applications. Tremendous quantities of information are generated annual Iy but fail to reach the designers, manufacturers, owners and installers in a meaningful format. Because of the current fragmented industry, this function will not be performed outside of DOE. A concentrated effort in gathering available technical information and disseminating it to the industry is needed.

Energy Distribution. A problem which has degraded the potential performance of active systems in the past has been the lack of adequate integration with the conventional system. This includes the auxiliary back-up subsystem as well as the distribution subsystem. Much of the problem is due to poor design which should get better as more experience is gained. Although problems do exist, DOE funded research is not justified. Anticipated improvements will come from training, experience and technology transfer.

Absorber Development. The performance of state-of-the-art absorbers and selective surfaces is high and could be improved little. The cost and durability of the absorber materials, however, must be improved but industry will do this on their own. Turbulence enhancers and non-linear $\alpha / E$ coating materials to avoid high stagnation temperatures are areas of possible research but realistically offer little potential benefit.

Storage. Three fundamental problems appear to exist with storage: durable liners for liquid tanks, heat loss from storage (air and liquid) and improved stratification in liquid systens. Information on which liners perform well needs to be disseminated based upon field performance. Better techniques for insulating storage containers need to be developed. Often the problem of excessive heat loss is the result of poor installation practices. The improvement of stratification in tanks may require further research although maximum use should first be made of available information.

Modeling and Simulation. Few of the systems currently installed require the use of detailed modeling and simulation. Most of the research involving parameter and configuration studies for conventional solar systems has been done and one can expect to gain 1 ittle through additional modeling. The exceptions to this are simulations which may be required to develop improved design tools and to evaluate the performance of tested systems for rating purposes. Work is done in this area will not be performed by industry but might be performed by academicians without significant support from DOE.

Test and Eyaluation Procedures. With DOE support, considerable progress has been made in the development of standard test methods and evaluation procedures for various materials, components and solar hot water systems. Several of these test methods are being used in industry rating and certification programs. However, there is a need for converting the results of the standard tests to long-term thermal performance estimates and ratings. Because of the unique characteristics of different systems, rating methods have been developed which are inappropriate for all systems, such as those which use noon instantaneous efficiencies or clear day data only. Research is required to define improved rating procedures as well as methods for converting test results into thermal performance estimates. Industry has not successfully accomplished this and may build in system 
biases if left to their own. DOE should play an active role here in cooperation with the various rating and certification groups.

Consumer Awareness. Although consumer awareness is a major factor in the ultimate market success of solar products, it has little to do with system effectiveness research. DOE should, however, recognize the adverse effect that published poor performance results have had in the past. These results are extrapolated by consumers to all solar systems this making it difficult for quality systems to penetrate the market. This is another reason why the test programs should be carefully designed. Information on systems performance should point out the successes as well as the problems.

Heat Transfer Fluids. The development of new fluids with all the desirable characteristics required by indirect solar systens (i.e., nontoxic, non-boiling or freezing, non-corrosive, etc.) would be helpful to some manufacturers but does not represent significant potential for cost or performance improvements.

Mirror Reflectivity and Durability. Due to the unique potential advantages of systems using evacuated tube collectors with reflectors, research on mirror materials, emphasizing reflectivity, durability and cost, should be pursued. Because of the small size of the industry segment manufacturing evacuated tube collectors, this type of basic materials research will probably not be adequately performed without DOE support.

Glazing Development. Performance improvements due to glazing development are doubtful for state-of-the-art flat plate collectors. The development of low cost, thin film collectors was not considered here because it was assumed to be a part of an advanced system development program. The use of polymers rather than glass offers scme potential for improvements in cost, weight and safety but durability remains a major problem. The small potential gains do not warrant an expensive polymer development program.

Machines. The development of more cost effective and better performing machines relates primarily to solar cooling. Because of the extremely high cost and poor performance of these components, considerable potential exists for improving the situation. However, it is doubtful that changes to current cooling system machines will ever successfully reduce cost sufficiently. A Second Law analysis has also indicated that bench test performance of the single effect machines are as high as can be expected, thus only field performance can be improved.

\subsection{Control Subsystem Meeting Recommendations (August 9-10, 1983)}

\subsubsection{Problem Areas}

Control subsystem problem areas that inhibit the effectiveness of active solar energy systems are listed and prioritized in Table 3. An indication is also given as to whether the problem area should be addressed by DOE or manufacturers. DOE-sponsored controls research would help to:

1. ensure that satisfactory products and methods are developed; and

2. quantify the benefits of controller products (hardware and logic) so that industry can make appropriate decisions regarding the design and manufacture of controllers. 
Table 3. Problem Areas for Active Solar Control Subsystems

Suggested Activity for

Priority DOE Manufacturer

1

\#

2

3

4

5

6

7

8

9

10

11

12

13

\#

\#

\#
Problem Area or

Solution Needed

Control strategies to provide optimum performance of system types (including sensitivity analysis).

More complete models and their validation.

Algorithms and implementations to result in correct set point or mode selection.

System fault detection and indication concepts.

Recommended practices for testing and installation.

Sensors fail catastrophically.

Sensors are incorrectly placed.

Sensor calibrations drift.

System integrators/installers do not understand the operating benefits of potential control functions. Need education.

Installation practices are poor.

Customer service.

Strategies to meet consumer and utility needs have not been identified. Potential problem.

Control system usability by consumer-man/machine interface.

Incorrect strategies.

Controllers fail or cause failures.

Controllers and related component hardware are not designed for the application - fail to follow good design practice. 


\section{3 .2 Objectives}

Recommended objectives for a DOE-sponsored controls research program are as follows:

1. Develop control strategies and more accurate models for improved system performance.

2. Develop standard test methods and evaluation procedures for:
a. Controller hardware
b. Controller interfaces

3. Perform sensitivity studies to determine the effects of sensor drift, sensor placement, etc.

4. Develop system fault detection and indication (hardware and software).

5. Improve the reliability of sensors.

6. Improve the understanding of system integrators and installers.

7. Develop standard specifications for sensors and controllers.

\subsubsection{Status of Current Research}

A background paper on control research has been prepared and is included as Appendix B of this report. It includes a review of control theory, a comprehensive literature review, and recommendations for further research. The interested reader may wish to refer to Appendix B for further details. However, a concise review of current research activities pertinent to the above-mentioned objectives is contained in this section. These activities address key areas, and are the basis for recommended future research activities.

\section{A. CONIROL STRATEGIES FOR IMPRONED PERFORMANCE}

Recent simulation work conducted at the University of Wisconsin, Madison, Wisconsin, has indicated that significant improvements in solar domestic hot water (SDHW) system performance may be realized by decreasing the collector flow rate in order to achieve a greater degree of thermal stratification. The increase in collector efficiency due to lower collector inlet temperatures more than offsets the decrease in the collector heat removal factor due to the lower flow rates. Flow rates less than one-fifth the normally recommended flow rates are being considered. The lower flow rates may also result in lower parasitic losses.

The results of the simulation studies have been verified to a certain extent by experiments performed at the SDHW test facility at NBS. During tests of six independent SDHW systems, it was found that the highest fractional energy savings were realized by a single-tank thermosypon direct system and that the high perforamnce was due to low collector flow rates 
that, in turn, resulted in thermal stratification of the storage medium. This is very important work in that it indicates that the system designers, manufacturers, and instal lers may not be using the best flow rates and, in fact, are perhaps off by a factor of two or greater. When parasitic losses are considered, the flow rates being used at present may be too high. Although the results obtained so far are significant, the work is not complete. The optimal flow rates should be determined for a wide variety of system types, both for space heating and SDHW systems and in various locations. In particular, indirect systems should be analyzed, and parasitic losses should be considered in all analyses. The effects of the hot water load profile on the optimal flow rate should also be examined, along with devices that promote stratification. It is important that this area be investigated in more detail since the recommended flow rates are so far different from those presently being used in typical installations.

As mentioned in the Appendix B, adaptive control has important applications in solar heating when the building parameters are not accurately known. Adaptive controllers utilizing real-time estimation techniques, although not as common as the digital and analog controllers, have been developed and evaluated in a commercial scale building. Further analysis and modeling is needed to determine the cost effectiveness of the increased performance of these controllers.

\section{B. TEST METHODS FOR CONIROLIERS}

Recent tests performed at the Solar Energy Research Institute (SERI) have revealed various problems with controller hardware. Sensors failed to meet published specifications after going through characterization and stagnation tests. At low temperatures, the responses of the thermistors varied by as much as 4 degrees $F$. The self-heating of the thermistors caused changes on the order of 2 degrees $F$. The quality of construction of the thermistors caused certain types of thermistors to be seriously affected by the stagnation tests.

Functional tests of the controllers showed deviations from the published manufacturers' specifications. The differential temperatures for the starting and stopping of the pump varied with the temperature of the sensors. When the sum of the deviations from specifications for the sensors and controller is considered, it is possible for the value of the collected energy to be negative.

These tests are important to the controller manufacturers. However, the tests should be expanded to include more controller types and additional environmental conditions. A review comittee, comprised of manufacturers and DOE/SERI/NBS personnel, should be formed to provide advice regarding the tests to be performed.

In addition, sensitivity studies should be conducted in order to ascertain the effects of sensor drift, sensor placement, and controller set points on system performance for the types of systems presently being used. *In the SERI tests, a failure was considered to have occurred if the sensor drifted out of its specified accuracy. This may not have led to any degradation in

* One recently published study is "An Analysis of the Effects of Active Solar Energy System Control Sensor Degradation on System Performance," R. B. Farrington, W. Short, SERI/TR-253-2185, July 1984. 
system performance. For example, the two degree drift of sensors due to the self-heating may not have an impact on the performance of the controller if both the collector and the storage sensor have the same drift rates (the absolute temperature measurement would be in error, but the relative measurement between sensors would be within specifications).

Controller manufacturers vary in recommended sensor location. Location of sensors and controller set points must be considered as a set. Collector sensors are normally placed on the absorber plate or in the fluid return immediately adjacent to the collector. Storage sensors are normally placed near the bottom of the storage tank (either inside or out) or next to the storage tank in the return fluid line to the collector. The sensor response time for the various sensor locations, combined with the optimum controller set points, needs to be reviewed to ensure proper performance under real world environmental and material conditions.

\section{FAULT DEIECTION}

Several manufacturers presently include monitoring and display systens with their controllers. This is a marked improvement from the initial bang-bang controllers which usually had a small LED to tell when the system was collecting energy. The present day monitoring controllers still rely on the thermistor to provide the technician with temperature readings for system analysis. None of the existing controllers have the capability to determine if the sensors have drifted since installation, a possible problem identified by SERI.

There are controllers that can record maximum and minimum temperatures, number of times the pump was turned on, measure the approximate heat output of the solar system, and identify shorts or open thermistor circuits, lowflow or no flow conditions, reverse thermosyphon flow and low supply voltage. These controllers are a step in the right direction toward builtin-test-equipment and fault-detection systems. However, these systems rely on proper sensor installation and accurate sensor performance. Faultdetection systems need to be independent of the controller sensor and be capable of verifying the performance of the controller.

\section{MODELING}

The prime method for evaluating various control strategies and determining the accepted practices for controllers is the modeling of the system based on real world examples. First, the component and the system models are developed; the driving functions, control objectives and the control execution are determined; and sensitivity of the model established by computer simulation.

The model then needs to be verified and validated by testing at facilities such as SERI, NBS or other qualified laboratories. Environmental limits of operation could be determined that would assist in developing specifications for the controllers and their sensors. Simulations could be run that would assist in determining the validity of fault detection concepts. Controller set points could be provided for the various sensor locations. 
Recommended research activities that are required in order to solve control subsystem problems (Table 3) and address the objectives stated earlier are listed below.

Task 1. Control Strategies

1.1 Determine the optimal mass flow rates for solar space heating and DHW systems.

1.2 Investigate the controller function based on stagnation temperature (see Appendix B, p. 55).

1.3 Determine the effects of cycling on system performance (see Appendix B, p. 56).

1.4 Determine partial excitation characteristics of pumps and blowers in relation to proportional controllers (see Appendix B, p. 56).

1.5 Examine the performance of multi-rate circulators (see Appendix B, p. 57).

1.6 Examine proportional, proportional-integral-differential (PID), and adaptive controllers for the distribution of energy (see Appendix B, p. 59).

Task 2. Test Methods

2.1 Develop standard test methods and evaluation procedures for controller hardware.

2.2 Develop standard test methods and evaluation procedures for controller interfaces.

Task 3. Sensitivity Studies

3.1 Determine system performance sensitivities to sensor drift.

3.2 Determine system performance sensitivities to sensor placement.

3.3 Determine system performance sensitivities to set point.

Task 4. Fault Detection Methods

4.1 Develop fault detection methods for anti-freeze systems.

4.2 Develop fault detection methods for water systems.

4.3 Develop fault detection methods for sensors.

3. RESEARCH RECOMMENDATIONS FOR ADVANCED ACTIVE SOLAR ENERGY SYSTEMS

In a recent DOE Active Program Research Requirements (APRR) Study [2] a number of advanced heating and cooling systems were identified as pranising concepts for the year 2000. These systems are listed in Table 4. 
Table 4. Primary APRR Advanced Systems

1. Residential Direct Heating and Hot Water, Liquid

2. Residential Direct Heating and Hot Water, Air

3. Residential Open Cycle Solid Desiccant Cooling, Heating, DHW

4. Commercial Solid Desiccant/Vapor Compression Hybrid Cooling and Heating

5. Commercial Absorption Cooling

6. Commercial Rankine Power Generation and Cooling

7. Ground Coupled Solar Assisted Heat Pump Commuinity Heating (96 Apts.)

While the APRR study identified costs and performance of these systems, relilability issues were not addressed. Accordingly, it is the purpose of this section to identify research requirements for addressing potential reliability problems with these advanced systems.

In many cases, these advanced systems will face the same reliability problems as conventional systems. Since these problems are addressed elsewhere, this section will focus only on new reliability issues unique to the advanced systems. Each system will be discussed separately with both system and component reliability issues addressed in each case. It should be understood that since these advanced systems have not yet been built, the identification of reliability issues involves a considerable amount of hypothesis and speculation. Wherever possible, this speculation will be an extrapolation of what we know about the reliability problems of existing systems [3].

\subsection{Residential Direct Heating and Hot Water-Iiquid}

This system consists of a closed collector piping loop with drainback to the storage tank whenever the pump shuts off for freeze protection. A significant feature of this system is the use of plastic pipe, chlorinated poly (vinyl chloride) (CPVC) or polybutylene (PB), in place of more expensive copper pipe. These plastics are typical ly limited to $200 \mathrm{~F}$ and cannot be attached directly to a stagnating absorber plate. Usually acetal or brass fittings are used to connect lengths of PB pipe while CPVC pipes are typically joined by adhesives. The reliability of these joints is an important research area.

Several different collector concepts have been proposed to lower costs. Thin film collectors must be capable of withstanding stagnation temperatures (as must any of the collector concepts) and must be able to withstand the local steam pressure produced when the collector is filled. For drainback systems not employing a trickle flow, the collector must be able to withstand the system vapor pressure and the elevation head present at the base of an array of collectors connected in series. Since a major 
thrust is to use materials less expensive than copper, the corrosion of these materials must be addressed. This is largely a system reliability concern since proper inhibitors must be employed in the collector loop. For collectors using plastic materials the long tem effects of ultraviolet radiation and high temperatures must still be addressed as well as compatibility with corrosion inhibitors. Thermal stability of adhesives and selective surfaces are also critical.

Several of the advanced concepts call for the use of a heat pipe heat exchanger on the load (DHW) side to reduce pumping power. Since this is a new concept, the reliability of this component needs to be addressed.

Several of the liquid systems are to employ low cost storage tanks. A drainback system need not employ a tank that can withstand 125 psig. A lower pressure tank would need only to withstand about $15 \mathrm{psig}$ in a closed drainback configuration for a residential application and could potentially be less expensive than a 125 psig tank. Whether such a tank would be as reliable as conventional pressurized DHW tanks needs to be determined. Plastic tanks would have problems similar to those of plastic piping.

\subsection{Residential Direct Heating and Hot Water - Air}

This advanced system would be a typical air heating system but would employ a less expensive air collector, such as a fibre mat absorber with plastic glazing. Although the biggest question about this type of collector is performance, reliability issues associated with the details of assembly need to be addressed.

As in the advanced liquid systems, a new heat pipe load side heat exchanger warrants investigation. Other than the heat exchanger and collectors, this air system is essentially conventional and one can expect the typical reliability problems associated with air systems, e.g. leaks.

\subsection{Residential Open Cycle Solid Desiccant Cooling, Heating, DHW}

This is an open cycle system of the Munters type which uses a desiccant wheel to dry air which can then be evaporatively cooled. Even the "conventional" version of this system is still experimental. The advanced system would employ a parallel passage dehumidifier wheel. Reliability issues include the maintaining of passage spacing with time and the long term durability of the parallel passage base material (e.g., Mylar) and the desiccant material when exposed to temperature and humidity cycles. Maintenance of the seal between supply and return air is also a critical factor. Although a rotary heat exchanger and evaporative cooler are conventional components, their maintenance in a residential systems environment needs to be addressed.

Because this is a multi-component air system, leakage can be expected to emerge as a major reliability concern. Also the control system in any combined heating/cooling system is relatively complex and can be a source of problems.

\subsection{Commercial Solid Desiccant/Vapor Compression}

This system combines the dehumidification of a desiccant system and the sensible cooling of a vapor compression subsystem. potential reliability 
problems for the desiccant subsystem are similar to the previous system. The addition of two more components to the air stream increases leakage sites, and the control system is samewhat more complex. Research is needed to develop low cost leak-free dampers and simplified controls. Since the vapor compression unit is modified and not simply off-the-shelf, its reliability would be in question.

\subsection{Commercial bsorption cooling}

This system uses a solar-fired absorption chiller which contains an integral gas backup boiler. Because of the high firing temperature of the chiller, high performance collectors (e.g., of the evacuated tube/CPC type) are required. These are still in the development phase and durability of the tubes and reflectors are serious questions. The integral absorption chiller/gas boiler is new, especially when one considers that the chiller design is thermodynamically advanced (e.g., double effect). Further complication results from the need for a heat rejector in the collector loop.

As in any absorption cooling system, but particularly for this advanced design, controls can be expected to emerge as a major reliability concern. This system is extremely complex because of the effects of chilled water and cooling water temperatures, interaction of gas backup, and use of storage (hot side and/or cold side).

\subsection{Commercial Rankine Power Generation and cooling}

This system uses solar heat to run a Rankine cycle engine which drives the compressor of a heat pump to supply cooling and also spins a motor/generator to produce electricity. Both the Rankine and vapor compression cycles would share the same evaporatively cooled condenser.

Like the absorption chiller system, the Rankine cycle system requires high collector delivery temperatures. The SERI low cost parabolic trough concept is considered the collector of choice. This collector is cabledriven on the rim, and its accuracy is affected by the durability of the cable. Like any trough the reliability of the tracking/drive system is critical and the reflector surface and substrate can degrade with time. If the system is designed such that boiling takes place in the collectors, the reliability of water quality control comes into question.

A major area of reliability concern is the Rankine cycle engine itself, particularly the seals. Development of a long lasting turbo-compressor will be needed for this type of system to work. As in the case of the absorption chiller, control complexity is high, particularly if variable speed pumps and fans are used.

\subsection{Ground Coupled solar Assisted Heat Pump Community Heating}

This system uses a dual source heat pump (low cost collectors and the earth) for the heating of community buildings. An array of deep wells containing U-type heat exchangers is employed, and the ground is used as storage for seasonal carryover. Thin film plastic collectors open to the atmosphere are used with a lined sheet metal tank for storage, plastic piping, and drain-back protection. 
Reliability issues are similar to those of liquid direct heating systems with the additional complications of the heat pump and ground-coupling. Ground heat exchangers have traditionally faced problems associated with various soil conditions.

Degradation of the contact between the heat exchanger and the ground, and freezing of the ground can have a significant impact on heat transfer. Drying of the soil due either to thermal cycling or shielding of rainfall by surface insulation can reduce performance. Underground leaks are also a potential reliability issue. Since the heat exchange wells are covered by insulation and the collector array, access for maintenance can be a problem As in the case of the liquid direct heating system, reliability of thin film plastic collectors is a serious issue.

\section{SUMMARY}

\subsection{State-of-the-Art Systems}

Based on recommendations presented in Section 2, the following research areas (listed in priority order) are recommended for DOE support in order to improve the effectiveness of state-of-the-art active solar hot water and space conditioning systems.

1. Control subsystems. This includes investigation of control strategies, development of test methods and determination of system performance sensitivities and fault detection systems.

2. Materials. For various materials (e.g. insulation, piping, ducts, tank liners, heat transfer fluids, reflectors, glazing, absorptive coatings), research should be conducted to develop:

- Durability data under various in-use conditions;

- Test and evaluation procedures to aid in long-term performance predictions; and

- Material selection quidelines to assist in choosing materials for various system applications.

3. Systems Performance. In regard to the collection and evaluation of field performance data, more emphasis should be placed on subsystems or component performance, cost, reliabililty and maintainability. Field and laboratory testing of systems should continue, as appropriate, to support modeling and simulation, design tools, and test and evaluation procedure development.

4. Technology Transfer. Available research data and information is not being successfully disseminated to potential users. Accordingly, more government effort is needed to gather available information and to transmit it to industry in a useful and timely manner.

5. Design Tools. The development and validation of better design tools and guidelines is another high priority area which should be emphasized in the DOE research program. 


\subsection{Advanced Systems}

In regard to the advanced active solar energy systems presently being studied by DOE (Section 3), the following research areas (not listed in priority order) are recommended for DOE in order to address important systems effectiveness factors (thermal performance, cost, and durability/reliability).

1. Materials

- Plastic piping (including joints)

- Plastic glazing and absorber plates

- Dessicants (solid and liquid)

2. Components

- Thin film collectors

- High temperature collectors (including reflectors and tracking devices)

- Heat exchangers

- Controls

- Open-cycle regenerator/collectors

- Absorption chillers/heat pumps

- Dessicant chiller/dehumidifiers

5. REFERENCES

1. "Program Plan for Reliability and Maintainability in Active Solar Heating and Cooling Systems," Mueller Associates, DOE/CS/36010-01, October 1980.

2. "Active Program Research Requirements (APRP)," Final Report, Vol. 1, W. B. Scholten, J. H. Morehouse, Science Applications, Inc., DOE/SF/11573-TI (Vol. 1), October 31, 1983.

3. "A Summary and Assessment of Historical Reliability and Maintainability Data for Solar Hot Water and Space Conditioning Systems," Gary J. Jorgenson, Solar Energy Research Institute, SERI/TRI-253-2120, May 1984. 


\section{APPENDIX A}

DEVEIOPMENT OF A PRIORITIZATION MEIHODOLOGY FOR THE SYSTEM EFFECIIVENESS RESEARCH PROGRAM AT THE U.S. DEPARTIMENT OF ENERGY 


\subsection{INIRODUCTION}

The System Effectiveness Research (SER) Program has emerged from an earlier DOE program which dealt with reliability and maintainability of solar systems. The new definition of SER, however, encompasses additional factors which impact on a system's ability to provide cost effective service. Figure 1 il lustrates the many elements which combine to determine the system effectiveness. The two key elements are thermal performance and annualized cost. These two factors combine to determine the cost per million BTU's the system realizes.

The goal of the SER program is to conduct research which will improve this cost effectiveness figure for solar systems. Because of the large number of proposals for research which are encountered relative to a limited budget, it is necessary to prioritize the areas of research based on a rational set of criteria. This appendix describes a methodology for accomplishing this prioritization and discusses its preliminary use during the August 2-3, 1984 NBS meeting. It is suggested that the methodology be refined and used in future planning cycles.

\subsection{Elements of the SER Program}

Figure A-I suggests that there are two key factors to system effectiveness; thermal performance and cost. Many elements comprise each of these areas. To facilitate the evaluation process the elements under thermal performance have been separated into two categories; those which represent improvements to a state-of-the-art properly operating system and those which represent improvements of field installed systems so they can operate closer to the expected performance.

Annualized costs can also be thought of as being comprised of two factors; those which reduce the cost of the system and those which extend the life of the system. A discussion of each of these areas is presented below in section 1.2.2.

\subsection{Method for Prioritizing Research Areas}

Research, by definition, involves the acquisition and interpretation of new knowledge. This suggests that the prioritization of research activities will inherently be fraught with uncertainty of success and benefit. However, this does not necessarily mean that the prioritization cannot be undertaken systematically with bounds applied to at least the potential benefit of each activity. The methodology developed for this study seeks to establish these bounds and provide initial evaluation of priorities. The methodology and conclusions can then be reviewed by other researchers and managers to obtain consistently formatted input.

The methodology consists of a number of phases. The first deals with the identification of factors which contributed to either a reduction of thermal performance from an ideal system or the incurrence of a cost. As shown in $\mathrm{F}$ igure $\mathrm{A}-1$, these two areas are the elements which comprise the "system effectiveness".

The second phase involves the establishment of bounds for improvements in each of these areas. This provides an appreciation of the relative 


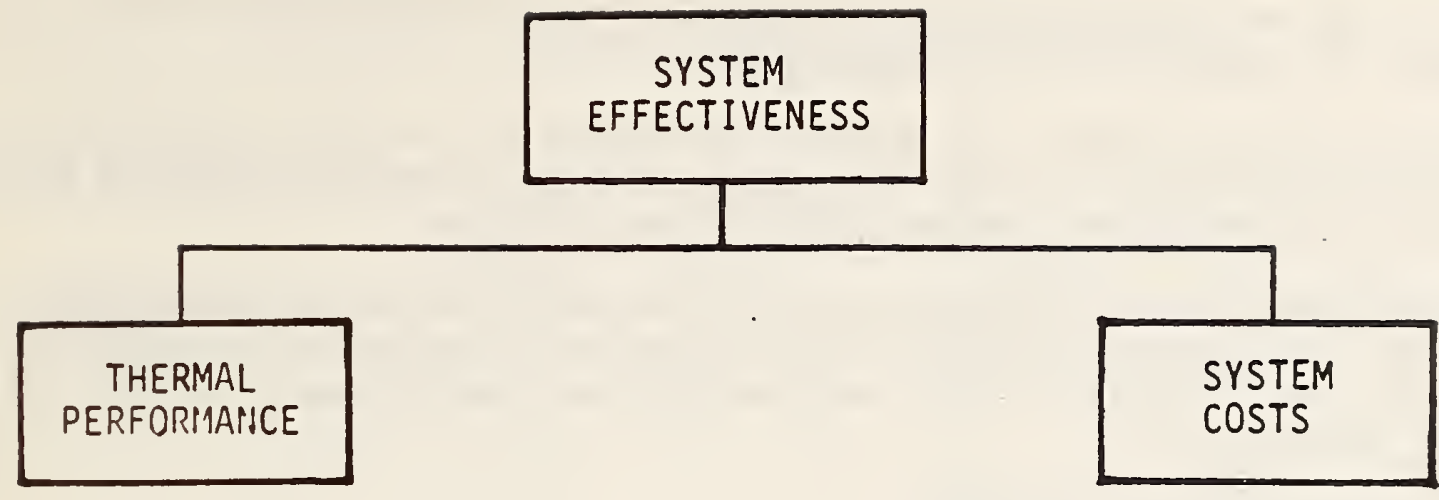

\section{Sources of Degradation}

- Parameters

- Nonideal design parameters

- Installation effects on parameters

- Changes in material properties

- Nonoptimal Design

- Design tool error

- Wrong parameter values

- Site constraints

- Errors in weather data

- Control strategy

- Downtime

- Component Failure

- System Replacement

- Inefficient Operation

- Leaks

- Control system malfunction

- Load profile

\section{Sources of Performance Improvement}

- Collector

- Absorber

- Glazing

- Back and edge coefficients
Sources of Incurred Costs

- Component Materials

- Collectors

- Controls

- Storage

- Plumbing (pipes, valves, etc.)

- Pumps

- Heat exchangers

- Fluids

- Conversion Equipment (heat pumps, chillers)

- Support structure

- Ducting

- Overhead and Profit

- Installation

- System Design

- Maintenance (component life)

- Replacement (system life)

- Parasitics

- Pumps

- Fans

- Controls

- Other Equipment

- Storage Losses

- Load Profile

- Control Strategy

Figure A-1. Factors in System Effectiveness 
potential for various activities. It is expected that these bounds will be a function of application and system type.

The third phase involved subjecting each area to screening factors which determine if work in this area falls into the general purview of the DOE Solar Heat Technology System Effectiveness Program.

The fourth phase is the evaluation of each area of research which passed the screening criteria with respect to a number of evaluation criteria. The results of this evaluation can then be used to rank the research activities.

\section{2 . Identification of Factors}

Figure A-1 illustrates the typical factors which affect the thermal performance and annualized cost of an active solar syster. The importance of each of these factors varies from system to system and application to application. It is recommended that the list shown in Figure 1 (page 2) be made system specific for future planning cycles by consulting industry and research personnel.

\subsubsection{Establishment of Bounds}

The lists in Figure A-1 provide an overview of the factors which affect cost and performance, but they do not indicate the potential gains which could be achieved by performing research in any one of the areas. An understanding of the limits of improvement for any one activity area allows the development of rational priorities amongst activity areas. For example, research on selective surfaces for flat plate absorbers might be a very interesting area to fund research but if the research is directed toward improving thermal performance then the limit to improvement over current systems might be determined to be quite low.

It was not possible to establish these bounds for thermal performance improvement for all system types in such a short period of time. However, what was determined was that for properly operating, state-of-the-art active solar systems of most types and applications, the system efficiency should be 35-45\%. Field data of numerous sites indicates that installed systems are realizing an efficiency of 0 to 418 with most below 25\%. (See Table A-1). This discrepancy indicates that substantial gains might be possible in improving performance toward the expected performance. The areas where performance degradation is taking place must be identified and serve as a basis for future research prioritization.

In a manner similar to the breakdown of performance degradation described above, the costs over the lifetime of a systen should be broken out to identify what costs could be reduced and by how much. If distribution networks are imposing high overhead costs on solar systems, then a simple reduction in collector costs may not accomplish proportional reductions in system costs. Thus a thorough understanding of cost and pricing structures within the solar industry should be prepared to better prioritize projects aimed at cost reductions. Several studies (Booze Allen, DHR) have performed such a study but these need to be updated and performed for more system types to allow project prioritization. 
Table A-1. Measured System Performance of NSDN Sites

(\% Efficiency)

Space Heating \& DHW

\begin{tabular}{|c|c|c|c|}
\hline Liquid & Air & $\mathrm{DHW}$ & Space $\mathrm{H} \& \mathrm{C} / \mathrm{OHW}$ \\
\hline 25 & 13 & 41 & 7 \\
\hline 21 & 13 & 35 & 5 \\
\hline 18 & 13 & 34 & 4 \\
\hline 12 & 10 & 33 & 3 \\
\hline 12 & 8 & 32 & 3 \\
\hline 12 & 7 & 31 & 2 \\
\hline 11 & 5 & 28 & 2 \\
\hline 11 & 3 & 28 & 0 \\
\hline 10 & 3 & 27 & 0 \\
\hline 7 & & 26 & 0 \\
\hline 6 & & 25 & 0 \\
\hline 5 & & 24 & -1 \\
\hline 5 & & 24 & \\
\hline \multirow[t]{8}{*}{2} & & 23 & \\
\hline & & 22 & \\
\hline & & 21 & \\
\hline & & 13 & \\
\hline & & 13 & \\
\hline & & 13 & \\
\hline & . & 12 & \\
\hline & & 4 & \\
\hline 11 & 8 & 24 & 2 \\
\hline
\end{tabular}


Projects aimed at extending the life of the system is an effective method for improving the cost effectiveness of the systems. Component reliabilities for field installed systems must be understood to base prioritizations in future plans.

The thermal performance and cost data described above will serve as guidelines in developing research priorities. However, there are a number of factors which require more subjective input. To accomplish this, screening and evaluation criteria have been developed. The evaluation criteria allow the integration of the quantitative performance and cost data described above with the subjective factors such as probability of success, etc. These criteria are described, in the following sections.

\subsection{3 screening Criteria}

A research activity undertaken by a program within the DOE should meet general suitability requirements imposed by the stated mission of the Department. The current administration has indicated that the DOE should be involved in long-term, high risk research which would not be accomplished by other organizations if not funded by the DOE This broad policy statement can be put into two "Screening Criteria" which must be passed before an activity can be considered for funding. These screening criteria are:

- High Risk/Long Term Payoff

- Not Performed by Industry or Elsewhere

These criteria are self explanatory and reflect the current administration's policy.

1.2.4 Evaluation Criteria

Assuming that a number of research areas are identified which pass the screening Criteria it then becomes necessary to evaluate the relative worth of each area to DOE in achieving its system effectiveness objectives. The fol lowing Evaluation Criteria are recammended in this methodology:

- Potential Contribution Toward Achieving Cost Reductions (5)

- Potential Contribution Toward Achieving Performance Improvements (4)

- Probability of Success (3)

- Cost to Program (2)

- Time to Complete Research or Reach First Major Milestones (3)

These criteria reflect the importance of an activity area but they are not necessarily of equal importance. To account for this, weighting factors are used to indicate the relative importance of one criterion to another. The weighting factors used in this evaluation are shown above in parenthesis. 
To arrive at a total weighted score for a research area the criteria score's $(0-10)$ are multiplied by the weighting factors, and then the products are summed.

\subsection{USE OF METHODOLOGY (AUUUST 2-3, 1983)}

Major factors (thermal performance and cost) affecting the effectiveness the various types of active solar energy systems was the initial topic at the August 2-3, 1983 meeting. Although the pre-meeting information package contained a preliminary quantification of: (1) various sources which cause degradation or improvement in system performance and (2) system costs, the industry participants believed the current data base on system performance and costs was inadequate and could not be used at this time for establishing research priorities.

The second item discussed was a list of proposed research areas which would be considered for prioritization. The final list which was developed by the participants contained 18 research areas (Table 1). Proposed evaluation criteria and weighting factors for ranking the list of research areas was the next item considered. After discussion, the proposed evaluation criteria and weighting factors were revised. The revised values are shown in Table A-2 and were used by the industry participants to establish the prioritized list of research areas at the August 2-3, 1983 meeting (see Table 2).

Table A-2. Evaluation Criteria and Weighting Factors Used At August 2-3, 1983 Meeting

\section{Evaluation Criteria}

1. Potential contribution toward achieving cost goals

2. Potential contribution toward achieving performance goals

3. Probability of success

4. Cost of program

5. Criticality to technology success

6. Time to complete research or reach first major milestone

7. Durability and reliability
Weighting

Factors

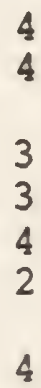


The following guidance was also given in determining criteria scores: Criteria Number

\section{Comment}

$1,2,7$

3

0 = Strong negative importance

5 = Neutral

10 = Strong positive importance

10 = Strong positive importance

$0=$ Poor probability

4

$0=$ High cost to DOE

$10=$ LOW cost to DOE

5

$0=$ Not critical

$10=$ Critical

6

$0=$ Long time

$10=$ Short time 


\section{APPENDIX B}

Solar Heating and Cooling Control Subsystems

\section{by}

C. Byron Winn and

Peter Armstrong

June 1983 
1. Introduction...................................... 33

2. Review of Control Theory...................................... 34

3. Controls Literature Review............................... 47

4. Recommendations for Further Research........................ 54

References.....................................................64 


\section{INTRODUCTION}

This paper has three main sections: "Review of Control Theory," "Literature Review," and "Recommendations for Further Research." The objective of the "Theory" section is to provide readers with a common knowledge base of control concepts and nomenclature. Some readers may skip most of this section by quickly scanning it for underlined words and noting their usage. The objective of the "Literature Review" section is to show where research in solar heating and cooling controls now stands. While the 1 ist of cited references is fairly comprehensive the discussion is necessarily limited, being mainly an effort to enumerate the control topics that solar researchers have addressed and show how the work of different researchers is related.

The objective of the "Further Research" section is to stimulate thought and discussion. It is a frankly biased catalogue of promising areas of controls research that would benefit the solar industry and, in some cases, the electric utilities and other providers of back-up energy. Readers are invited to suggest additional research topics. 


\section{REVIEW OF CONTROL THEORY}

The control of solar energy systems is quite similar to the control of any dynamical systom that is subjoctod to disturbanoos. A great deal of work has been done in this area and it may be applied to controllers of solar energy systems. Before examining specific types of controllers used in solar energy systems we shall first review some basic control theories. Consider first an example of a classical control problem as illustrated in Figure 1.

The objective is to vary the energy input to the heater in order to control the enclosure temperature $\mathrm{T}_{\mathrm{E}}$. Usually the enclosure temperatore is controlled in order to maintain some desired temperature, $T_{D}$. The deviation of $T_{E}$ from $T_{D}$ should be small regardless of the magnitude of disturbances, $G$ (sunshine), $T_{A}$ (outside temperature), and $V_{W}$ (wind speed). There are several ways to do this.

The simplest form of control is "open loop" control. In this caso the heater is energized on some schedule regardless of the current enclosure temperature. Obviously this type of control would not result in very high comfort levels.

An improved type of open loop control is possible by measuring $G, T_{A^{\prime}}$ and $V_{W}$. A predetermined function of these variables is then computed and the furnace is energized if the function exceeds some predetermined threshold. This type of closed loop control will perform well if the function and threshold are properly selected (not an easy task) and provided no disturbances (such as open windows) are introduced. Also the need to measure these variables is a burden.

The controller is simplified and the comfort level is improved by using "closed loop" control, as illustrated in Fig. 2. 


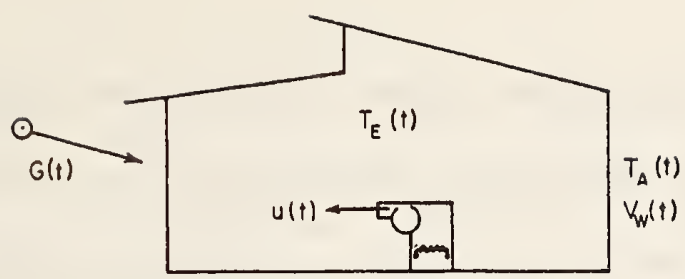

Fig. 1. Control of building temperature.

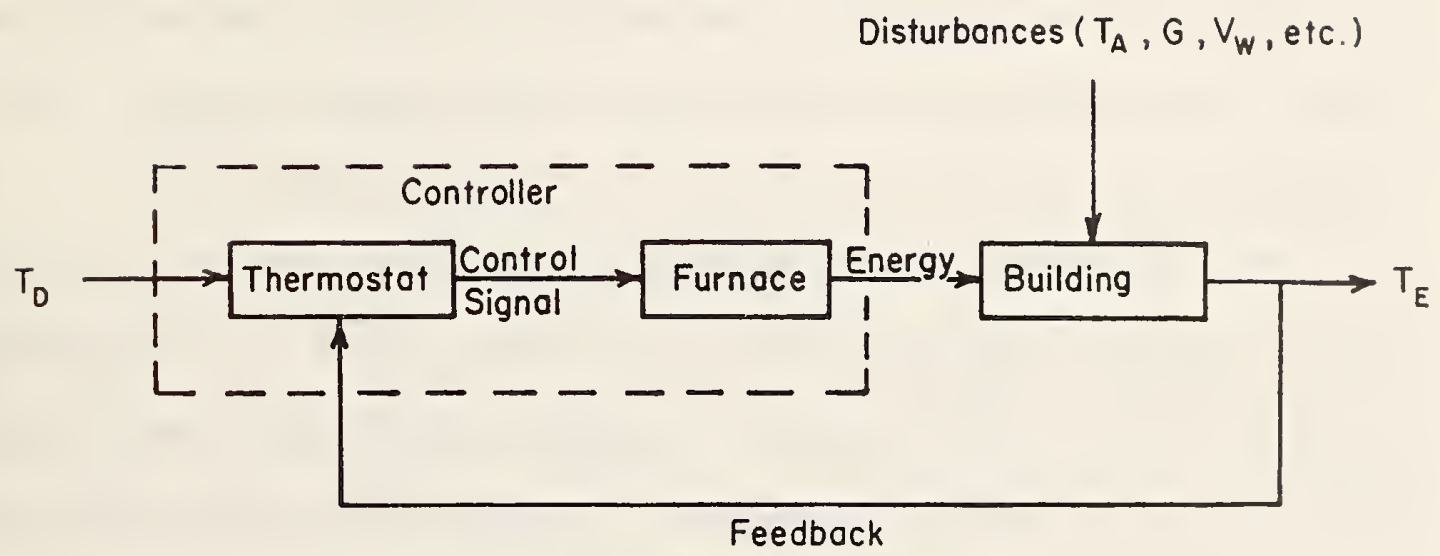

Fig. 2. Feedback control systems.

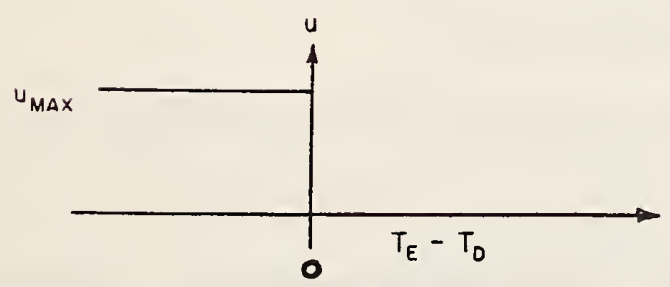

Fig. 3. Bang-bang control.

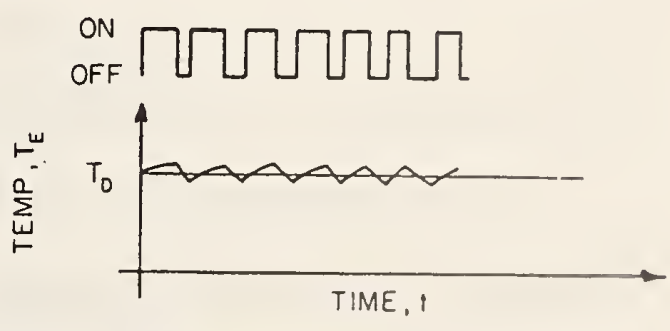

Fig. 4. Time variation of temperature (bang-bang controller). 
Bang-Bang Contro1

In this case the thermostat serves as the first element of the controller and compares the actual room temperature, as sensed by the thermostat, with the desired room temperature, as set in the thermostat.

The final control element, the furnace, has only two "states" - full on or off - depending on the state - closed or open - of a switch (relay) operated by the thermostat. When the temperature at the themostat falls below the desired temperature, the switch is closed, causing the furnace to operate, and consequently increasing the room temperature $T_{E}$. When $T_{E}$ exceeds $T_{D}$ the switch is opened and the furnace is shut off.

This would also be an undesirable controller since it would lead to rapid "cycling" (on and off) of the furnace. That is, the controller would turn the furnace on whenever the enclosure temperature is sensed to be less than the desired temperature, no matter how small the difference. This could result in a rapid increase in $T_{E}$, depending on the furnace output and the ambient conditions, such that $T_{E}$ exceeds $T_{D}$ and the furnace is turned off. This type of controller is referred to as a bang-bang controller. It has only the two states, on or off. It is represented in Figure 3. The building temperature response that would result from use of this controller is illustrated in Figure 4.

The enclosure temperature is maintained at the desired value but at the cost of excessive cycling of the furnace. The cycling rate may be reduced by introducing a "deadband" into the controller. The effect of the deadband is that the controller will not turn the furnace on until the enolosure temperature drops bolow the "bottom of the deadband;" the controller will then keep the furnace on until $T_{E}$ increases to boyond the "top of the deadband" . This is illustrated in Figuro S. The control 


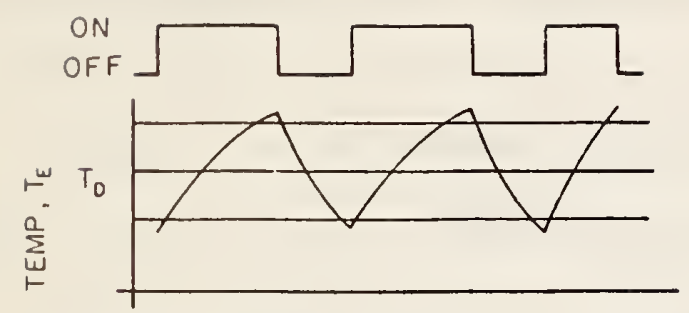

Fig. 5. Time variation of temperature (bang-bang controller with deadband).

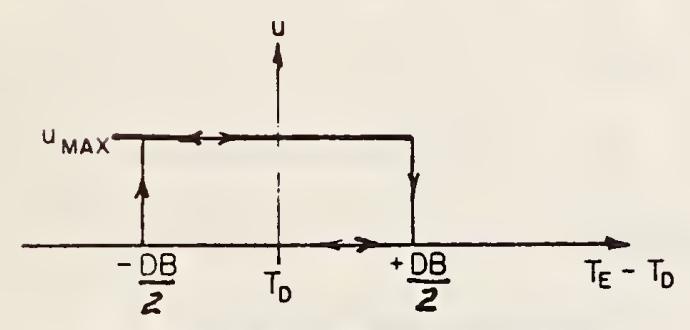

Fig. 6. Bang-bang control with deadband.

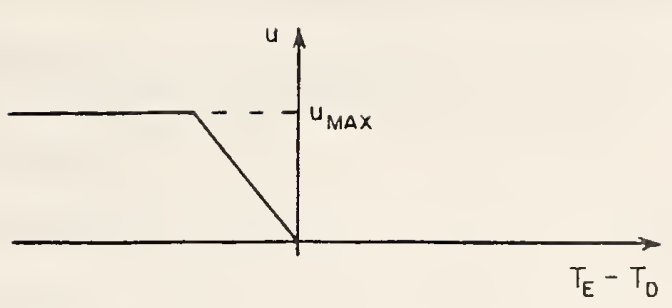

Fig. 7. Proportional controller (with saturation).

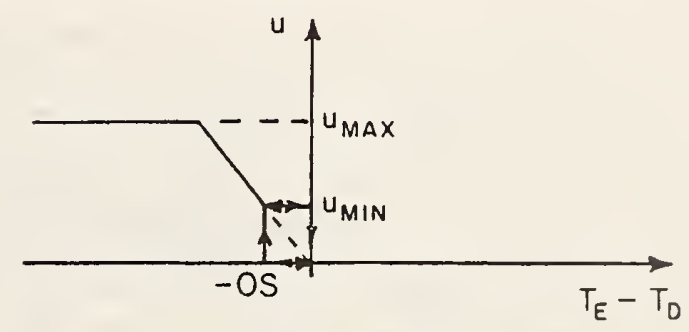

Fig. 8. Proportional controller (with saturation and oft̀set).

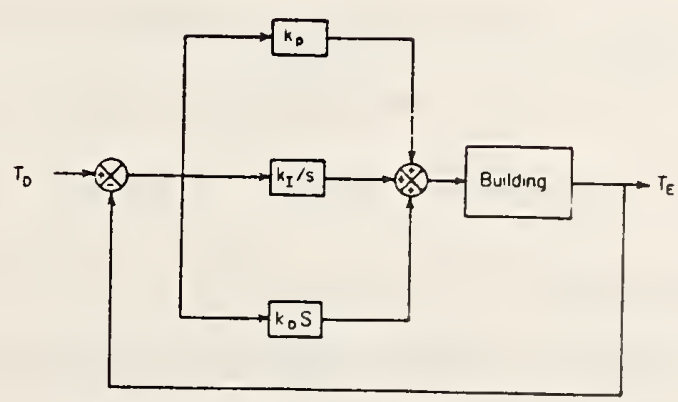

Fig. 9. Block diagram of PID controller. 
function (often reforrod to as the "control law") is illustrated in Figure 6 , and may bo expressed analyticaliy as

$$
u=\left\{\begin{array}{l}
u_{\text {JLAX }}, T_{E}-T_{D} \leq-D B / 2 \\
0, T_{E}-T_{D} \geq D B / 2
\end{array}\right.
$$

The bang-bang controller with deadband does not maintain as precise control of $T_{E}$ as does the bang-bang controller without deadband, but it results in much less cycling. However, it also results in "overshoot;" that is, the enclosure temperature will exceed the top of the deadband and fall below the bottom of the deadband. Normally this is of 1ittle consequence in bailding heating systems. However, with the advent of buildings having large "thermal capacitances." the problem of overshoot becomes more significant. Cycling and "Overshoot" are characteristics of bangbang controllers, regardless of the system being controlled.

\section{Proportiona1 Control}

The overshoot may be eliminated by using "proportional control." In the case of proportional control, the output of the furnace is proportional to the difference between the enclosure temperature and the desired tem perature. Thus, if the room temperature is very low, the furnace will work hard to overcome the temperature error. However, as $T_{E}$ approaches $T_{D^{\prime}}$ the output of the furnace will decrease, thereby preventing overshoot from occurring to the extent it occurs with a bang-bang controller. The control law for the proportional controller may be written as

$$
u= \begin{cases}k_{p}\left(T_{E}-T_{D}\right), & T_{E} \leq T_{D} \\ 0, & T_{E}>T_{D}\end{cases}
$$

and is illustrated in Fig. 7. The slope of the line, $k_{p}$, is referred to as the controller gain.

The principal disadvantage of the proportional controller, as 
illustrated, is that it would cause the furnace to operate continuously as long as $T_{E}$ is less than $T_{D}$. This problem can be avoided by including an "offset," as illustrated in Fig. 8. In this case, the controller will not turn the furnace on until $T_{E}$ is less than $T_{D}$ by the amount $O S$. The control is proportional to the magnitude of the temperature error, $\left|T_{E}-T_{D}\right|$, for $T_{E}-T_{D}<-O S$. It then remains constant at the value $U_{\text {min }}$ until $T_{E}$ exceeds $T_{D}$. There will still be some overshoot with this controller.

\section{Integra1 Contro1}

An additional type of control that may be used is "integral control." An integral controller is designed to increase the controller output (the furnace output in our example) in proportion to the time integral of the error. That is, the longer the enclosure temperature remains below the desired temperature, the more the furnace output will be increased. This is represented analytically as

$$
u=k_{I} \int_{t_{0}}^{t}\left[T_{E}(t)-T_{D}(t)\right] d t
$$

An integral controller does not result in a fast response, but does have a stabilizing effect on system response.

\section{Derivative Control}

If quicker responses are desired, then "derivative control" may be used. A derivative controller leads to a control output that is propor tional to the rate of change of the error. That is

$$
U=k_{D} \frac{d}{d t}\left(T_{E}-T_{D}\right)
$$

Thus, the controller output increases as the time rate of change of the error increases. Derivative controllers lead to quick responses, but tend to be unstabilizing and are strongly affected by noisy signals. 


\section{PID Controllers}

The above control types may be combined to result in a "proportiona1-integra1-differentia 1 controller," known as a PID controller. The control $1 \mathrm{aw}$ is expressed as

$$
u=k_{p}\left(T_{E}-T_{D}\right)+k_{I} \int_{t_{0}}^{t}\left(T_{E}-T_{D}\right) d t+k_{D} \frac{d}{d t}\left(T_{E}-T_{D}\right)
$$

A PID controller can potentially reduce energy consumption in three ways. First, it reduces overshoot in heating the space (an improved method of thermostat "anticipation.") Second, if it is desired to implement a proportional actuator, the PID controller could increase the average steady state efficiency of a given size combustion heat exchanger by operating the burner at less than nominal rating most of the time. And third, the PID controller may increase transient efficiency by reducing on-off cycling and reduce flue losses by causing the heat exchanger to be at a temperature that is well below the nominal design temperature at the end of each "on" cycle.

Using the concept of a transfer function, which is defined as the ratio between the output and the input, both expressed in the frequency domain, the equation for the PID controller may be vitten as

$$
\frac{U[s]}{E[s]}=k_{p}+\frac{k_{I}}{s}+\frac{k_{D} s}{s}
$$

The "transfor function" is shown in blook diagram form in Figure 9. Design of Contro11ers

There are two basio approaches to the design of controllers. The first is referred to as trial and orror, whilo the second is referred to as the analytical design approach. These are briefly described below. 


\section{Trial-and-Error_Design}

The "trial and error method" is illustrated in Figure 10. The tria1 and error method is the method that is most often used in the design of control systems. This is further illustrated by Figure 11, which depicts unity feedback control system. In this figure, the output from the system. $c(t)$, represents the controlled output. The desired response is represented by the input to the block diagram and denoted as $r(t)$. The controller is a proportional feedback controller and is represented by the gain, $k_{p}$, acting on the error signal, $e(t)$. The desired response could be interpreted as the enclosure temperature in our example. In the classical trial and error design procedure, one would select a set of performance specifications and then attempt to adjust the controller gain so that the performance specifications rould be satisfied. A typical set of performance specifications relative to a step input to a second order system is illustrated in Figure 12. For the building heating problem discussed previously, one would be primarily concerned with overshoot and final error. The trial and error design process tends to be inefficient and expensive and, when one selects a set of performance specifications, one has no way of knowing whether or not those performance specifications can be satisfled.

Some general guidelines, drawn from experience, can ameliorate these problems somewhat by suggesting a reasonable initial control strategy.

\section{Design_Guide1ines}

Almost all the temperature control problems in solar applications are heat transfer problems, and are characterized by long time constants and slow reaction rates. Distance-velocity lag (also known as dead timo) is common. The measurement 1 ag can pose a serious problem. The measurement time constant depends on the mass and surface area of the sensor or probe 


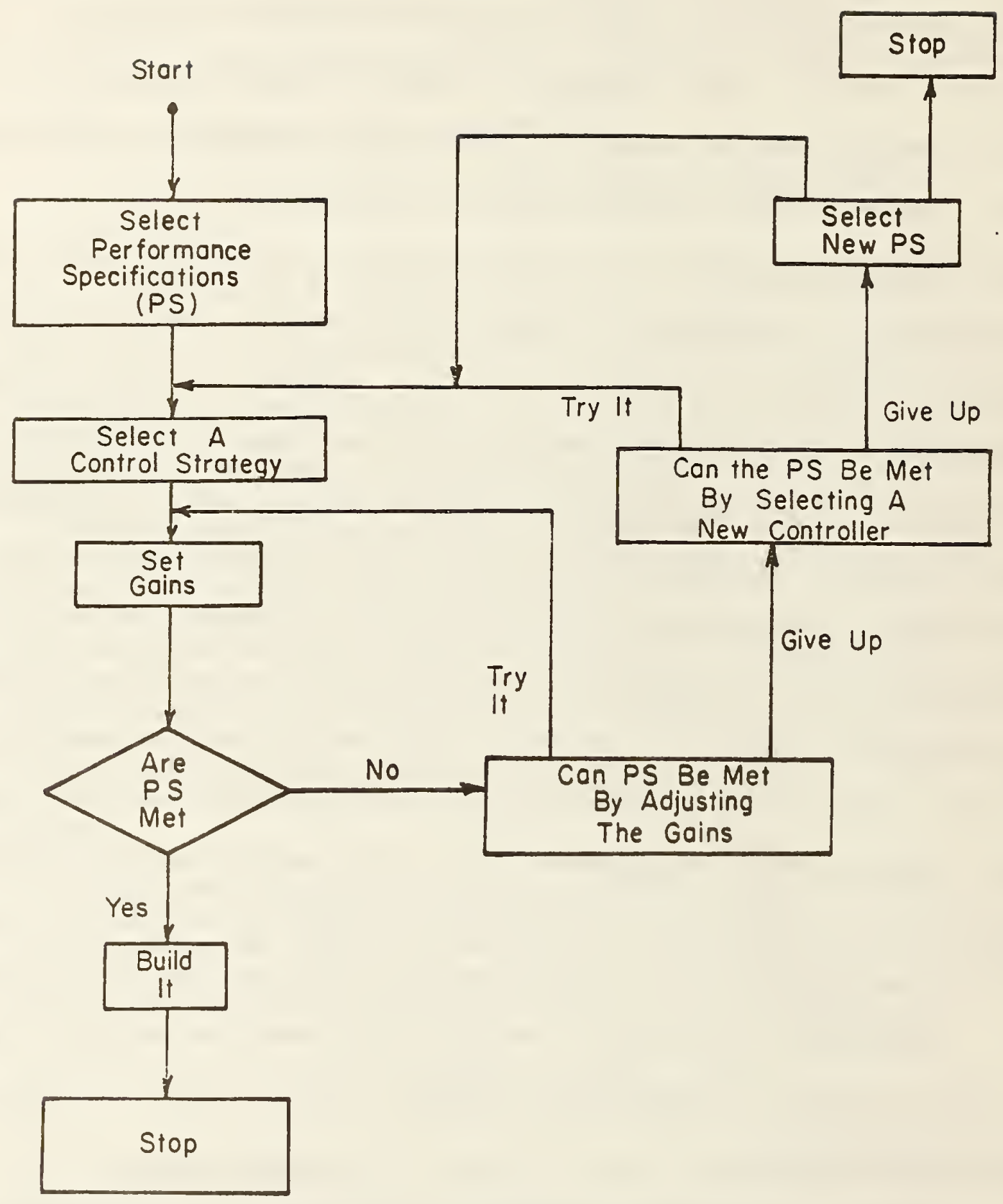

Fig. 10. Trial and error design procedure. 


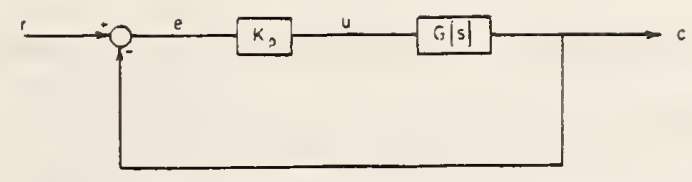

Fig. 11. Block diagram of a "classical" proportional controller.

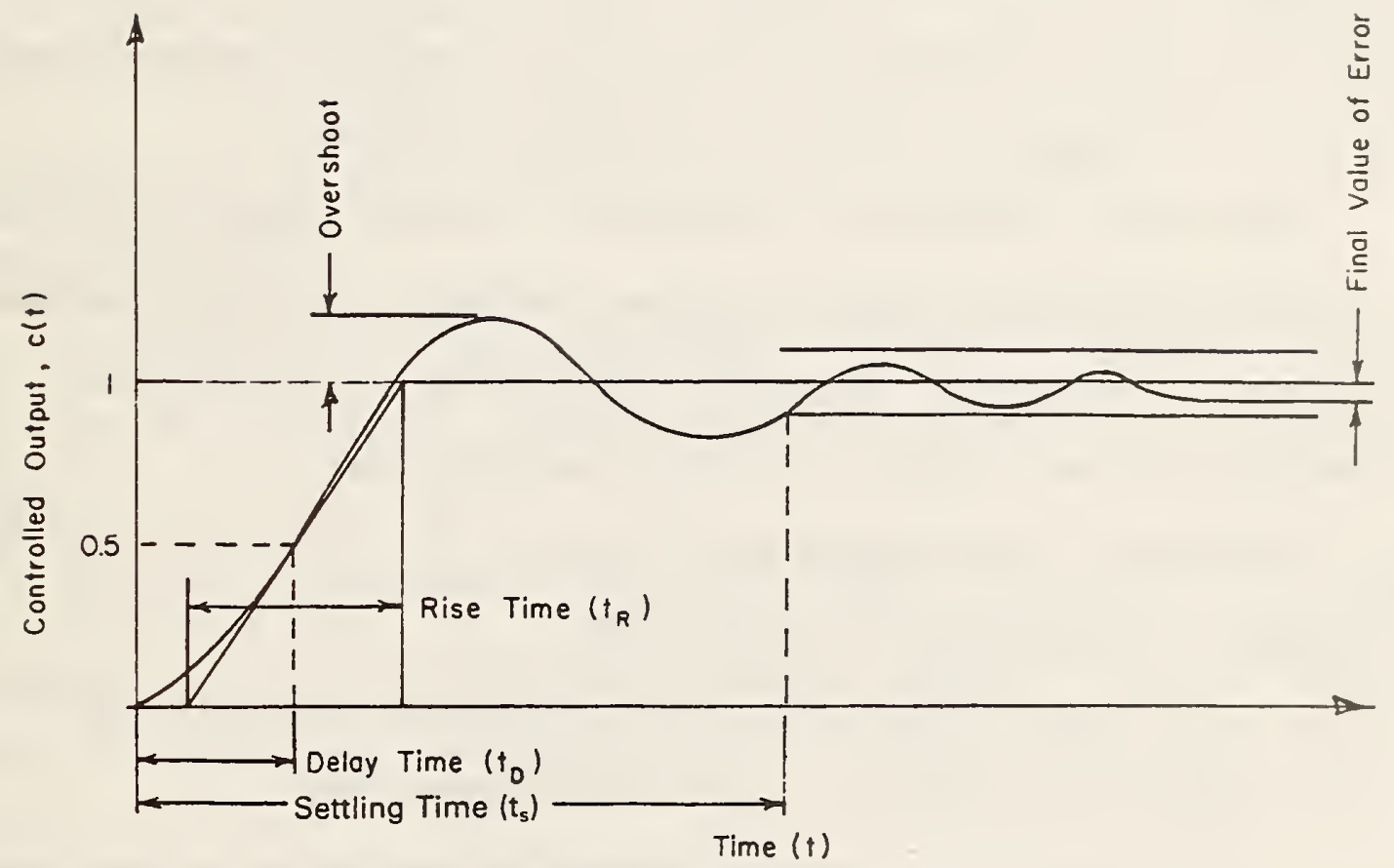

Fig. 12. Typical time domain performance specifications. 
assembly, the fluid being measured, and its volocity past the probe.

Processes dominated by one large capacity, for erample, storage tanks in air hoating systems, can bo controlled with on-off controllers.

Proportiona1-plus-reset control is used in smallor capacity systems where load changes are large and where distance-velocity and measurement lags are important. Most hydronic collectors and shell and tube heat exchangers fall into this category. Derivative control becomos holpful provided the distance-velocity $1 \mathrm{ag}$ is not the dominant secondary dynamic element, for example, as with an air heating collector.

Controlling temperature by miring hot and cold streams is more nearly a blending problem than a heat exchange problem. Good mixing and fast temperature measurement are the keys to simplifying the control job. Proportiona1-plus-integral controllers should be used.

In general, the following guidolines can be used in selecting controllers. Uso proportional control where

o the cycling action, due to on-off control, is undesirable;

- set-point changes are sma11 or infrequent; and

- the steady-state deviation between tho set point and tho process variable, that is, the offset, can be tolerated.

Use integral control where

- the offset must be reduced or eliminated, and

- the set point changes are frequent.

Do not add integral control when

- start-up overshoot must bo oliminated, and

- the process can be controlled with high-gain proportional control.

Add derivative action to proportional control whon

- the distance-velocity lag (for example, dead time in the pipos) is smaller than oither of at least two linear lags (for examplo, storage tanks) in the process loop. 
Do not use derivative control if

- the distance-velocity $1 \mathrm{ag}$ is significant;

- the process is noisy.

It is not at all uncommon for considerable amounts of money to be spent on computer simulations in attempting to select a set of gains for selected controllers in order to meet a set of performance specifications. It is often more efficient to use an analytical design process in which the guesswork is eliminated and where one can determine directly the control strategy that will result in optimizing system performance.

\section{Analytical Design}

In applying the "analytical design" process, one selects a cost function to be optimized. Hence, it is often referred to as "optimal contro1."

A typical formulation of the optimal control problem is the "linear Iegulator" problem. This type of control is applicable to situations where the objective is to bring a control variable, such as $\left(T_{E}-T_{D}\right)$, to zero.

A linear Iegulator for this application could be designed to minimize the weighted sum of the root-mean-square deviation from the set point and the mean energy input:

$$
J=\int_{0}^{t_{f}}\left(A(U(t))^{2}+B(E(t))^{2}\right) d t
$$

where the deviation from the set point, $E(t)$, is related to the controlled energy input, $U(t)$ (and to other factors, such as weather and occupant behavior, which are both treated as noise) by a set of differential equations that governs the dynamic behavior of the heated space and backup heating plant. The chief parameters of concern in these govorning oqua- 
tions are the room parameters, the resistance to heat loss (R) and the thermal storage capacitance (C).

One of the issues raised by the integration of backup heaters with solar heated buildings is the interaction of controls. In particular, passive solar heated buildings present a number of problems. First, the "time constants" ( $T=R C)$ of rooms in such buildings are usually much longer than in conventional buildings because both $\mathrm{R}$ and $\mathrm{C}$ are much greater. The thermal capacitance effect alone has a major significance: any overshoot of the setpoint by the backup heater controller represents a relatively large quantity of energy absorbed by thermal capacitance elements. This overshoot will then persist (decay very slowly) because of the large time constant of the heated space. It is therefore apparent that significant energy savings can be realized by reducing overshoot and by reducing thermostat deadbands.

The quadratic criterion represented by equation (7) helps to reduce overshoot because increasing deviations, $E(t)$, are penalized with progressively increasing severity. The solution to (7) will also yield a control law with small final error because the first term penalizes deviations of the set point deviation. Since these penalties are integrated over time the resulting control $1 \mathrm{aw}$ will involve some integral feedback which will tend to reduce final error. Another useful feature of the optimal regulator is reduced peak demand. The quadratic penalty on $U(t)$ tends to 1 imit parasitic or auxiliary power. 


\section{CONTROLS LITERATURE REVIEH}

Some of the major review papers on solar energy controls include: Kutscher et. a1. (1982) and Su and Castle (1979) both emphasizing solar IPH contro1; Winn (1982) covering mainly residential systems, the determination of cycling rates for on/off controllers and control laws for proportionalonly control of collector circulation based on the Pontryagin maximum principle; Kent, et. a1. (1980) on residential DHF controls; ard Dorato (1979) on application of on/off singular linear quadratic and periodic optimal control theory to solar energy systems. Control and ineasurement refer ences, germane to, but not dealing specifically pith, solar erergy applications include Tierstein (1978), Roots (1969), Johnson (1964) and Shinsky (1974).

Selection of offset and deadoand faraneters (i.e. ( $\Delta \mathrm{T}_{\text {ON }}$ and $\Delta \mathrm{T}_{\mathrm{OFF}}$ ) for differential, on/off control of collector blorers or pumps is discussed by Davis (1975), Schiller, et a1. (1980), Duffie and Becknan (1980), Alcone (1981) and Winn (1982). On/off control strategies ase compared to proportional control strategies using simulation by Herczfeld and Fischl (1977) and Lewis and Carr (1978) and Schiller et al. (1980) and in field tests hy Schlesinger (1978).

Some of the problems encountered pith complex solar heating and cooling systems controlled by multi-function set point and differential on/off controllers are discessed by Guyaz (1978) and IuIjiz and Arütrong (1978).

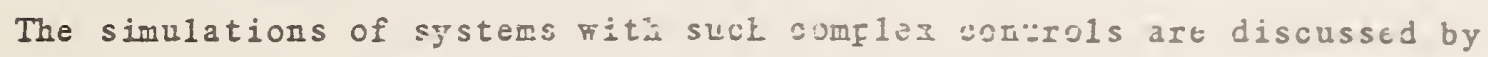
Orbach et. a1. (1978), by Armstrong and Bechtel (1979) and by Piessens et. a1. (1981). Design of and operating experience with a hardwaro programa able (not microprocessor based) controller used to "breadboard" complex control logic based on set point and differential comparisons bas been reported by Bechtel et. a1. (1979). 
One of the earliest papers on optimal utilization of solar energy in space heating and cooling applications was by Winn, Johnson and Moore (1974). A control-theoretic approach was used to examine the problem of minimizing the use of auxiliary energy required for space heating and cooling. It was shown that the auxiliary heat supplied to a solar heated house may be minimized by the use of a proportional plus integral state feedback controller. It was demonstrated that the controller that leads to minimizing the auxiliary fuel may be obtained from an application of optimal regulator theory. The possibility of implementing the optimal controller on a microprocessor was also discussed. The gains for the optimal feedback controller must be determined by solving a matrix Riccati equation, which proves to be a nontrivial problem. This situation was examined in more detail (Johnson and Winn, 1975) in order to develop efficient algorithms that may be used for efficient management of a building's energy budget and that may be implemented on a microprocessor. In a simplified analysis of the problem of controlling temperatures in buildings (Winn and Hu11, 1978) a comparison between several different heuristic control strategies and an optimal control strategy was presented. The optimal control strategy that minimizes the integral over time of the sum of the building energy requirements and a measure of occupant discomfort was developed and it was shown that energy savings could be realized through implementation of the optimal control strategy. The analysis was extended (Winn and Hu11, 1976) to include sensitivity studies and was further extended (Winn and Hu11, 1977) to include analysis of the singular control problem.

An early study relating to the impact of solar systems on utilities (Soot, Goldbach, and Winn, 1975) examined the problem of solar domestic water heating in the northwestern part of the United States and the poten- 
tial impact on Pacific Power and Light Company.

The above-mentioned control studies dealt primarily with the problem of controlling the solar heating or cooling system from the point of view of minimizing fossil fuel consumption and maintaining occupant comfort. The principal analytical tool that was used in these studies was that of simulation.

Winn (1982) compares the process of selecting controller parameters by trial and error (using simulation to evaluate performance) with penalty function techniques of analytical control synthesis. For example, Johnson (1964) describes a general technique for determining on/off control parameters using a quadratic penalty function. Somasundarum et. a1. (1978) made some simplifications to Johnson's approach to obtaining an explicit solution for control of a large solar heating and cooling piant. One of the first attempts to apply the penalty function approach to solar heating systems was by Kovarik and Lesse (1976). Other application studies were hy Johnson and Yinn (1975), Auslander, et, a1. (1979), Blodgett, et al. (1978a) and Winn and Hul1 (1978). One of the problems with the optimal control approach, pointed out by Auslander et. al. (1979) and Blodgett et. a1. $(1978 b)$ is the effect of errors in plant parameter estimates on controller performance. The solution to this problem, adaptive control, is discussed later in this review.

Another problem that must be Faced regardless of whether the control parameters are selected by trial and error or analytical optimization is simplification in the plant model. For example Schindwolf (1981) shows how to select collector loop flow control parameters based on a lumped capacitance collector model. Orbach et. al. (1981) however show that control parameters derived under the assumption of a lumped capacitanco collector 
may be considerably in error. Wright (1981) presents a detailed method for determining control parameters based on a distributed capacitance collector model. Lumped load models, on the other hand, have been found satisfactory, e.g. Winn and Hu1l (1978, 1979) and Rink (1981). However, for the control of auxiliary heat for rooms in passive solar heated buildings, distributed capacitance models may be needed (Winn, 1982).

Some controllers have been built to implement a PID optimal regulator control law. These controllers were installed and tested as reported by Eisenberg et. a1. (1977) and by Winn and Hu11 (1977).

The utility load factor problem was addressed by Winn and Duong, (1977). An optimal control strategy was formulated to reduce the amount of auxiliary energy used and to avoid peak load hours for solar structures. The proposed strategy consisted of three interrelated operations. First, a short-term weather forecasting model based on the Kalman filtering approach was used to obtain the predicted values of the weather parameters (solar radiation, wind speed and ambient temperature). The amount of auxiliary electric energy required to be stored in order to satisfy the predicted heating load requirement for the nest day was then determined from the estimated amount of useful solar energy collected, the estimated heating load, the amount of energy available in the storage tank, and the expected losses by heat transfer processes. Finally, a linear programming scheme was used to determine the optimal electric energy consumption sequence and a self-tuning regulator was used to minimize the occupant discomfort. Additional papers that dealt with this problem were (Winn and Duong, 1978), (Lorsch, 0swald and Crane, 1978), (Debs, 1978), (Moe, 1978), (E1timsahy and Santos, 1977), (Debs, 1979), (Dorato, 1979) (Seba1d, et.a1., 1980), and (Winn, 1982). Weather prediction models suitable for implementation in 
microprocessor based controllers have been studied by Sinha and Sharma (1975) and by Hamlen and Hamlen (1976).

The studies mentioned above dealt primarily with solar heating and cooling systems and only secondarily, in some instances, with off-peak storage type devices. The possibility of using heat or cool storage and off-peak electricity for charging of the storage has not escaped consideration. A Luenberger observer was developed (Hays, Parkinson and Hinn, 1979) for accurately predicting ambient temperatures for up to 24 hours in advance and this has been built into the controller for an off-peak heat storage device and operated in one of the Colorado State University solar houses. Some of the hardware and software details for this device were presented in (Winn and Robinson, 1979). Additional energy storage systems were discussed in (Kalhammer, 1979), (Lorsch, 1980), (Winn and Finn, 1982) and (Winn et, a1., 1982).

In addition to the controllers, one must have an efficient mechanical system design, and efficient energy conversion hardware. There have been many papers ritten relative to the subject of efficient energy conversion equipment. In (Grot, 1975) the feasibility of combining various appliances that are now constructed separately into integral assemblies which would permit more efficient energy design, utilizing waste heat and minimizing the impact of appliance operation on heating and cooling systems, was considered. Single zone, single zone variable volume, multi-zone, dual-duct, terminal unit, etc. systems are described in (Shih, 1976) and the interrelationships between the fan systems / hydronic systems, the energy converting machines and the building are presented. Papers dealing spocifically With the hardware aspects of controllers in building climate control systems include (McNa11, 1976) and (Baitz, 1976) in which recommendations for 
government sponsored projects of $R$ and $D$ for energy conservation are presented. Also, in (Vanderweil, 1976) a review of the different types of HVAC systems, including fan coils, unit ventilators, closet units, induction units, self-contained units and incremental heat pumps was presented. Baumann (1979, 1981) describes how pump and valve characteristics affect flow control techniques in fluid loops. Another paper (Gajjar, 1976) described low cost techniques for monitoring and utilization of energy in rooms and zones of structures, and using these techniques to automatically control the temperature of the zones to effect a savings in energy. Heating system controller parameters that influence system efficiency and operating costs and that can be field adjusted, but for which no criteria for optimal adjustment have been developed, were discussed in (Bonne, et. a1. 1976). In addition both retrofit and new equipment aspects were covered, together with a breakdown of the operating costs and savings due to changes in fuel and electricity consumption. In another paper (Jones, et. a1.. 1976) a two stage analysis was conducted in which the energy requirements for an existing office building were examined in detail and the most promising opportunities for conservation were identified and then the potential impacts of the various possible conservation measures were evaluated. In another paper (Mrnka, 1976) various types of controllers were analyzed and their characteristics were described. Enthalpy control1ers, anticipatory controllers and olfactory controllers were discussed. An examination of sensor requirements for building control and energy management was presented in (Johnson, 1976). An analysis of the requirements for on-line management and supervisory strategies to control the interaction between system elements in HVAC systems was presented in (Anderson, 1976). Performance characteristics and relative costs of control elements such as 
dampers, valves for liquid and vapor, switches, relays, pneumatic and electric evacuators, and communication network requirements were discussed in (McNa11 and Buchanan, 1976).

As mentioned earlier, adaptive control may have important applications in solar heating and cooling because the plant parameters are not always accurately known. The parameter estimation techniques necessary to implement adaptive control are discussed by Pryor et. a1. (1980) and Pryor and Winn (1982). Adaptive contro1lers utilizing such rea1-time estimation techniques, and computing in real time the parameters necessary to implement an optimal regulator control were developed by Farris and Helsa (1978) and MacDonald et. a1. (1978) and evaluated after implementation in a conmercial scale building by Farris and Helsa (1980).

Designs of controllers for industrial process heat applications have been reported by Su and Castle (1979) and Gerwin (1980). Flow control for a high temperature (central receiver) system that could also be applied to low and medium temperature collectors is analyzed by De Rocher et. al. (1982).

Hardware designs for microprocessor based controllers are reported by Johnson and Winn (1975) and by Kent et. a1. (1978) and their implementation and testing are reported by Winn and Hul1 (1977), Eisenberg et. a1. (1977), Hoen and Lane (1978) and Hays et. al. (1978). 


\section{RECOMMENDATIONS FOR FURTHER RESEARCH}

From the foregoing 1iterature review a number of areas for further research have been identified. Some of the suggested research involves taking previous research topics to their logical completion. In these areas the tasks are fairly well defined. Other topics involve inquiries where the magnitude of improvements in cost or performance are harder to guess in advance. These areas of research will necessarily require of investigators a desire to embark on an uncharted course, defining new tasks and abandoning unpromising control concepts or analytical methods as the work progresses.

\section{Research on Controls for Collecting Solar Energy}

Huch research has focused on preventing cycling and maximizing solar energy collected or maximizing the difference between solar energy collected and parasitic energy.

\section{Bang-Bang_Controls}

Davis (1975) gave an expression for differential control set points that maximized the duration of collector operation subject to no ON/OFF cycling under steady state conditions:

$$
\frac{\Delta \mathrm{T}_{\mathrm{ON}}}{\Delta \mathrm{T}_{\mathrm{OFF}}} \geq \frac{\dot{\mathrm{mC}}_{\mathrm{p}}}{\mathrm{A}_{\mathrm{C}} \mathrm{D}_{\mathrm{L}}}
$$

Alcone (1981) corrected the expression for heat removal factor:

$$
\frac{\Delta \mathrm{T}_{\mathrm{ON}}}{\Delta \mathrm{T}_{\mathrm{OFF}}} \geq \frac{\dot{\mathrm{mC}}_{\mathrm{p}}}{\mathrm{F}_{\mathrm{R}}^{\prime} \mathrm{A}_{\mathrm{C}} \mathrm{U}_{\mathrm{L}}}
$$

In the foregoing expressions $\Delta T_{0 F F}$ is usually determined from the generally accepted constraint, $\operatorname{COP}=\frac{\dot{Q}_{\text {collected }}}{P_{\text {pumping }}} \geq 1$, which implies: 


$$
\Delta \mathrm{T}_{\mathrm{OFF}} \geq \frac{-\Delta \mathrm{p}}{\eta \rho \mathrm{C}_{\mathrm{p}}}
$$

where $\rho C_{p}$ is the heat capacity per unit volume of the collector fluid, $\Delta p$ is the collector loop friction loss and $\eta$ is the pump efficiency. Obviously the collected energy is maximized where there is no slack in the above constraints (i.e. they become equality constraints). In hydronic systems $\Delta \mathrm{T}_{\text {OFF }}$ is often on the order of $0.5^{\circ} \mathrm{C}$. This is as great or greater than the error bounds typically exhibited by thermistor temperature measuring devices. The effect of errors in determining whether or not the collector temperature rise exceeds the desired $\Delta \mathrm{T}_{\mathrm{OFF}}$ (e.g. probe error, thermistor/resistor bridge (mismatch) errors) has never been properly assessed.

Lunde has suggested a method for mitigating these errors by using stagnation temperature instead of collector outlet temperature. With this scheme the $C O P=1$ constraint gives the same expression for $\Delta \mathrm{T}_{O N}$ :

$$
\frac{\Delta T_{O N}}{\Delta p / \eta p C_{p}} \geq \frac{\dot{m} / C_{p}}{F_{R}^{\prime} A_{c} U_{L}}
$$

In principle one can make $\Delta \mathrm{T}_{\mathrm{ON}}-\Delta \mathrm{T}_{\mathrm{OFF}}$ arbitrarily small since (in contrast to collector outlet temperature) the stagnation temperature is not arfected by the pump state (ON or OFF). In practice, however, there is some thermal coupling between the collector fluid and the stagnation temperature sensor (i.e. the sensor suggested by Lunde actualiy measures some weighted average collector outlet and stagnation temperature). Although the effect of a $\Delta \mathrm{T}_{\mathrm{ON}}-\Delta \mathrm{T}_{\mathrm{OFF}}$ of $1^{\circ} \mathrm{C}$ or so should be small it has never been properly assessed. It will also be necessary to conduct field tests of this improved control strategy before it will be accepted by the industry. 
Winn (1982) has shown that the above constraint on $\Delta \mathrm{T}_{\mathrm{ON}} / \Delta \mathrm{T}_{\mathrm{OFF}}$ is conservative because some cycling is permissible (also inevitable since collectors do not operate in steady state) and because thermal capacitance effects result in rather slow cycling when it does occur. Winn derives a cycling $t$ ime of

$$
\theta(t)=\frac{m}{m}\left[\frac{\left.\dot{m} C_{p} / A_{c}\right) \Delta T_{O N}}{G(t)(\tau \alpha)-U_{L}\left(T_{s}(t)-T_{A}(t)\right)}-F_{R}+1\right]
$$

Thus the number of pump cycles per day is:

$$
N=\int_{t_{0}}^{t} \theta(t) d t
$$

Assuming constant $T_{s}$ and $T_{a}$ and that

$$
G(t)=G_{M} \operatorname{Sin}\left(\frac{\pi}{12} t\right), 6: 00=t_{1} \leq t \leq t_{f}=18: 00
$$

the expression for $N$ may be evaluated analytically to give $N$ as a function of $\mathrm{G}_{M}$ and $\Delta \mathrm{T}_{\mathrm{ON}}$. A suitable value of $\Delta \mathrm{T}_{\mathrm{ON}}$ that is less than the value given by $\Delta T_{O N} / \Delta$ OFF may then be selected.

The effect of such reductions in $\Delta \mathrm{T}_{\mathrm{ON}}$ on performance and cost should be evaluated in further research. A set of charts for specifying $\Delta T_{O N}$ might also be useful.

\section{Proportional and PID Control}

Proportional control is used much less than ON/OFF control in controlling collector blowers and pumps. This is due mainly to lack of information about efficiencies of pumps with motors run on less than rated excitation and thus to uncertainty that parasitic power can be much reduced. Work is proceeding at SERI into this and the related problem of controls and pumps for closed drain down systems where initial head is much greater than steady state head. It will be useful if the partial excitation 
characteristics of a number of pumps and blowers are characterized in this work.

A control scheme that combines some of the features of proportional control and of bang-bang control involves the use of multi-rate circulators. A multi-speed blower controlled by a microprocessor programmed to maximize the difference between collected and parasitic energy was tested in C.S.J. Solar House 2 by Hays et. a1. (1979). In hydronic systems it is practical to run two or more pumps in series or parallel in order to achieve the range of desired flow rates. (This scheme provides additional protection against collector stagnation due to pump failure as we11.) A relationship for specifying differential control thresholds for molti-rate circulators based on the steady state criterion for no cycling was derived by Armstrong (1979):

$$
\frac{\Delta T_{j \rightarrow j+1}}{\Delta T_{j \leftarrow j+1}} \geq \frac{F_{R_{j}} \dot{m}_{j+1}}{F_{R_{j+1}} \dot{m}_{j}}=\frac{1-\exp \left(-\frac{A_{c} D_{i}}{m_{j} C_{p}}\right.}{1-\exp \left(-\frac{A_{c}{ }_{j+1}}{\dot{m}_{j+1} C_{p}}\right)}
$$

where $\dot{m}_{j}$ is the mass flow rate with the multi-rate circulator operating at its $j^{\text {th }}$ rate, $\dot{m}_{j+1}$ is the next higher available rate, and the $A_{c} U_{j}$, $j=0,1, \ldots$, are the overa11 collector loss conductances (correspording to $F^{\prime} A_{c} U_{L}$ for a collector loop with just one flow rate) at the various flow rates, $\dot{m}_{j}$. The thresholds for transition to lower circulation rates, $\Delta \mathrm{T}_{\mathrm{j} \leftarrow \mathrm{j}+1}$, come from the COP criterion that is used to specify $\Delta \mathrm{T}_{\mathrm{OFF}}$ for the simple bang-bang control, thus:

$$
\Delta T_{j \leftarrow j+1}=\frac{\Delta p_{j+1}}{\eta_{j+1} \rho C_{p}}
$$

Note that this accounts for the nonlinear relation between pumping power 
and flow rate which unadorned proportional control does not.

A proper comparison of the costs of and long term performance resulting from use of bang-bang, proportional, and multi-rate controls for collecting solax energy should include analysis of systems with a range of collector, heat exchanger and storage parameters, and systems operating in a range of different climates. Current circulator efficiency curves, especially germane to proportional control, should be used as well as hypothetical efficiency curves that can be anticipated with improved motors and motor speed controllers. Variable speed control involving a nonlinear relation between $\Delta T$ and pump excitation power should be analyzed as we11.

A related topic that has received virtually no attention is the use of a PID input stage in a bang-bang or multi-rate output controller.

Winn and Winn (1981) have derived the optimal control that maximizes the difference between collected energy and parasitic energy when parasitic power is not directly proportional to m:

$$
J=\int_{0}^{t_{f}}\left(C_{1} \dot{Q}_{u}-P\right) d t
$$

where $\mathrm{P}=\mathrm{C}_{2} \dot{\mathrm{m}}^{\alpha}$.

Using an approximation for $F_{R}$

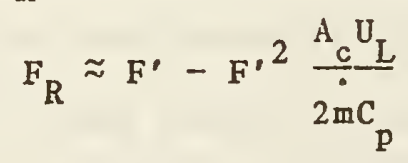

the resulting optima1 contro1 is:

$$
\dot{m}_{\text {opt }}=\left[\frac{\mathrm{C}_{1} \mathrm{fF}^{\prime 2} \mathrm{~A}_{\mathrm{c}} \mathrm{U}_{L}}{2 \alpha \mathrm{C}_{2} \mathrm{C}_{\mathrm{p}}}\right]^{1 / \alpha+1}
$$

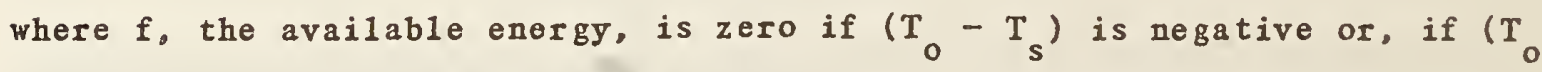
$-T_{s}$ ) is positive, determined from either 


$$
f=\dot{m C}_{p}\left(T_{0}-T_{s}\right) / F_{R}
$$

if the collector fluid mover is on, or

$$
f=A_{c} U_{L}\left(T_{0}-T_{s}\right)
$$

if the fluid mover is off.

This control is optimal for mixed storage systems. Note that $C_{1}$ can reflect the ratio of pumping energy to collected energy values. This may be useful if time-of-day rates apply to parasitic energy.

Recent work conducted at the University of Wisconsin, Madison, has indicated that significant improvements in SDHH system performance can be realized by decreasing the collector flow rate in order to achieve a greater degree of thermal stratification. The increase in collector efficiency due to lower collector inlet temperatures more than offsets the decrease in the collector heat removal factor due to the lower flow rates. Flow rates less than one-fifth the normally recommended flow rates are being considered. The lower flow rates also result in lower parasitic losses. This area should be investigated in more detail since the recommended flow rates are so far different from those being used in typical installations at this time. Research on Controls for Distributing Energy to the Load In active space heating systems, Winn and Hu11 (1979a, 1979b, 1979c) have shown that auxiliary energy use can bo redrced simply by zeducing overshoot in control of temperatures in the heated space. Optimal PID control laws were used to obtain the control improvements over conventional bang-bang controls. Even greater reductions in auxiliary energy can bo expected from auxiliary control improvements in passive buildings becauso of the larger thermal capacitances and longer time constants. One problcm 
in developing an optimal control $1 \mathrm{aw}$, however, is the variability of time constants in different heating zones due to the use of moveable insulation. This may be a promising application for adaptive control. The use of parameter estimation to implement such adaptive control should be investigated and the resulting effects on auxiliary energy use, peak demand, and overall heating costs in passive buildings should be evaluated.

Reduction of high coincident demand for auxiliary energy that conventional SHACS impose on utilities has been studied by Winn et. a1. (1982). One result of this study was an optimal off-peak storage control law that was then compared, by simulation of the solar space heating system, to a conventional control $1 \mathrm{aw}$ and to a suboptimal control $1 \mathrm{aw}$. The resulting solar load fractions, $f$, and total annual costs of supply, $c$, were:

\section{Conventiona 1}

(no off-peak)

f

c

$$
.51
$$

$\$ 2,932$
Suboptima1

off-peak control

$$
\begin{aligned}
& .52 \\
& \$ 2.749
\end{aligned}
$$

Optima 1 off-peak control

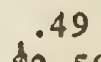

The cost reductions were due mainly to reduced utility capacity costs (i.e. end user demand charges).

Further investigation of the optimal off-peak control is needed because it assumes that the total load and solar energy collected over the on-peak period are known in advance. This typically requires a 12 hour weather prediction. An evaluation of the effect of weather forecast errors should be made. 


\section{System Simulation Studies}

At the present time there is a need for a simulation program that is useful in studying control strategies for solar heating and cooling systems. The TRNSYS program is perhaps the most widely used solar system simulation program at this time but, although a controller subroutine has been added to the program, it is not sufficiently general and versatile to allow for the study of numerous control strategies of interest. For example, proportional controllers, PID controllers, adaptive controllers, etc. cannot readily be examined using the present TRNSYS program. SIMSHAC, a simulation code developed in 1973-74, was developed for the purpose of conducting control strdies, but has not been updated since 1978. EMPSS and ELPS-2 were recently developed to study the impacts of solar heating and cooling systems on the electric utilities, but these programs require modifications to examine controllers. DOE-2 can be used for 1 imited controls studies but is also neither specific enough, nor general enough, to be very useful in studies of controllers.

It is recomended that one of the existing codes be modified to the extent that it may be used in controls studies so that improved strategies may be investigated. It is further recommended that experiments be per formed in an existing we11-instrumented systems test facility so that the code may be validated and various control strategies may be examined in a complete systems environment.

\section{HaIdware Studies}

SERI has recently conducted a study of solar domestic bot water systems in which comercially available controllers were purchased and then tested in a laboratory environment. The tests revealed problems with sensor accuracy, sensor failure, controller accuracy, failure to mect 
specifications, etc. Also, the tests were 1 imited in scope and did not include a wide variety of controller types. It is recommended that the problems with reliability of SDHW controllers that were identified in the SERI study be resolved and that additional, testing be performed, both on the controllers that were examined in the first phase of the work and on additiona1 contro11ers.

The recommended research activities are summarized in Table 1. 
TABLE 1. Summary of Recommended Research Activities

CONTROLLER FUNCTION/TYPE

Recomended Research

Quantify Parasitic Losses

Investigate Controller

Based on Stagnation

Temperature

Determine the Effects of Cycling on System Performance and Cost

Develop Charts for

Specifying $\Delta \mathrm{T}_{\mathrm{ON}}$

Determine Partial

Excitation Characteristics

of Pumps and Blowers

Examine Multi-Rate

Circulators

- Test Relationship for Differential Control

Thresholds

- Compare Costs and

Performance

. Test the Use of the

PID Input State in

Mixed Storage Systems

- Test the Performance

of Systems at Very Low

Fl ow Rates

Test Controllers that

Reduce Overshoot

Test off-Peak Storage

Controllers

Examine the Use of Weather

Prediction in Controls

Develop Control Systems

Simulated Program

Testing for Reliability
Collecting

Bang-Bang Prop. and PID

$\mathbf{x}$

$x$

$\mathrm{x}$

X

$\mathbf{x}$

$x$

X
Distributing

Bang-Bang Prop, and PID

$\mathrm{x}$

X

$\mathrm{X}$
X $\quad x$

X $\mathrm{X}$

$\mathbf{X}$

$\mathbf{X}$

X

\section{$x$}

$x$




\section{REFERENCES}

Alcone, J. H., 1981. "Simplified Methodology for Choosing Controller Set Points "- Solar Engineering - 1981: Proceedings ASME So1aI Energy Division Third Annual Conference on SSEA and Operational Results, Reno, NV.

Anderson, B., 1981. Solar Products Specifications Guide, Solar Age, New Hampshire.

Anderson, L. B. and H. E. Rauch, 1977. "Application of Optimization Techniques to Solar Heating and Cooling," Journal of Energy, Vol. 1, No. 1.

Anderson, P.A., 1976 (May). "Control Strategies for Building Energy Conservation - R D Opportunities, Energy Conservation in Buildings Through Improved Controls," ERDA Conference, Boston, MA.

Armstrong, P. R. and T. N. Bechte1, 1978 (June). "Integrated DiscreteState Controller Hodnle for TRNSYS," SSEA Conference, ASME, San Diego, CA.

Auslander, D. M., M. Tomizuka and H. Lee, 1979. "An Optimal Standard for Solar Heating Systems," Trans. ASME, J. of Dynamic Systems, Measurement, and Control 101, 138-149.

Baitz, A.G., 1976 (May). "A Control Manufacturer's View of Research and Development Needs for Energy Conservation," Energy Conservation in Buildings Through Improved Controls, ERDA Conference, Boston, MA.

Bauman, H.0., 1979 (May). "A Case for Butterfly Valves in Thrott1ing App1ications," Instruments and Control Systems, p. 35.

Bauman, H. 0., 1981 (June). "Control Valve vs. Variable Speedpump," Chemica 1 Engineering, p. 81 .

Bechte1, T. N., P. R. Armstrong, S. Karaki and G. D. Murphy, 1979. "A Pin-Programmable Controller for Research Systems," Proceedings ISES Conference, At1anta, GA.

Blodgett, R. E., J. R. Nebus and W. S. Trimmer, 1978a. "Optimal Control of a Solar Augmented Heat Pump System," Proc. First Workshop on the Control of Solar Energy Systems for Heating and Cooling, Hyannis, Mass., Published by the American Section of International Solar Energy Society, Newark, Delaware, 183-185.

Blodgett, R. E., J. R. Nebus, W. S. Trimmer and T. M. Tay1or, $1978 \mathrm{~b}$. "Sophisticated Solar Heating Controllers: Are They Cost Effective?" Proc. 1978 IFEE Conference on Decision and Contro1, San Diego, California, 203-205.

Eonne, U., J. E. Janssen, R. H. Torborg, A. N. J. Pearman, and L. W. Ne1son, 1976 (May). "Contro1 Modes of Residential Heating Systems," Energy Conservation in Buildings through Improved Controls, ERDA 
Conference, Boston, MA.

Debs, A.S., 1978. "Management of Electric Back Up Demand for Solar Heating and Cooling of Buildings," Proceedings of the First Workshop on the Control of Solar Energy Systems for Heating and Cooling. AS/ISES Publishing Office, University of Delaware, Newark, Delaware.

Chemical Engineering_Deskbook, 1979, (15 October). New York, HcGraw-Hi11.

Clark, E. F. and F. deWinter (Eds.) 1978. Proceedings of the First Workshop on the Control of Solar Energy Systems for Heating and Cooling, Hyannis, MA., Anerican Solar Energy Society Publishing Office, University of Delaware, Newark.

Davis, E. S., 1975 (January). "Stability of Differential Thermostats for Solar Collection Systems," California Institute of Technology, JPL, Pasadena, CA.

Debs, A. S., 1979. "Management of Electric Back Up Denand for Solar Heating and Cooling Application," Final Report, U. S. Department of Energy, Contract No. EGB-77-C-03-1595.

DeRocher, W. L., Jr., D. K. Melchior and R. K. McCordie, 1982. "Contro1 Simulations or a Molton Salt Solar Thermal Central Receiver," Solar Engineering - 1982, Library of Congress Card No. 81-65532.

Dorato, P. and H. K. Knudsen, 1979. "Periodic Optimization with Applications to Solar Energy Contro1," Automatica 15. 673-676.

Eisenberg, B. A., G. R. Johnson, D. V. Pryor and S. F. McCormick, 1977. "A Micro-Processor-Based Control System for Solar Heated/Cooled Residential Dwe1lings," Proc. 1977 Joint Automatic Contro1 Confer ence, 1157-1162.

E1timsahy, A. H. and E. A. Santos, Jr., 1977. "Controller for a Solar Heating System Utilizing a Time Varying Price for Electricity," Solar Energy.

Farris, D. R. and J. L. Melsa, 1978. "Energy Savings for a Solar Heated and Coolea Building Through Adaptive Optimal Control," Proc. 1978 IEEE Conference on Decision and Control. San Diego, California, 206213 .

Farris, D. R. and J. L. Melsa, 1980. "A Study of the Use of Adaptive Control for Energy Conservation in Large Solar Heated and Cooled Buildings," Proc. 19th IEEE Conf. on Decision and Control, 1214-1215.

Gajjar, J. T., 1976 (May). "Automated Individual Area Energy Control in Commercial and Residential Buildings," Energy Conservation in Buildings through Improved Controls, ERDA Conference, Boston, MA.

Gerwin, H. J., 1980 (August). "Field Experience with Solar Concentrating Collector Control Systems," Proc. 1980 Joint Automatic Control

Conf., San Francisco. 
Grot, R. A., 1975. "Integrated Household Appliances and Utility Services for Energy Conservation in Dwellings," Energy Conservation in Buildings Through Improved Controls, ERDA Conference, Boston, MA.

Guynes, B., 1978 (February). "Control Problems Encountered in Commercial Solar Projects," DOE Solar Controls Heeting, Washington, D.C.

Hamlen, S. S. and W. A. Hamlen, 1976. "A Distributed Lag Model to Predict Incoming Solar Radiation," Solar Energy, Vo1. 19, pp. 217-218.

Hays, D. K., C. B. Winn and G. R. Johnson, 1978. "A Microprocessor Based Optimal Solar Controller," Proc. First Workshop on the Control of Solar Energy Systems for Heating and Cooling, Hyannis, Mass., Pub1 ished by the American Section of the International Solar Energy Society, Newark, Delaware, 196-199.

Hays, D., B. Parkinson, and C. B. Wirn, 1979. "The Development of an Ambient Temperature Observer/Predictor (ATOP) for Use with Solar Heating Systems," Proceedings of the International Solar Energy Society.

Herczfeld, P. R, and R. Fish1, 1977. "Performance Evaluation of a Proportional Flow Control System," DOE E-8-77-5-02-4512.

Herczfeld, P. R., R. D. Klafter, R. Fischl and A. Orbach, 1978. "Study of Pump Cycling in the Control of Solar Heating and Cooling Systems," Proc. First Workshop on the Control of Solar Energy Systems for Heating and Cooling, University of Delaware, Newark.

Johnson, C. and W. H. Wonham, 1964. "Optimal Bang-Bang Control with Quadratic Performance Index," Trans. AS USE 86 6 D, 107.

Johnson, C.E., 1976 (May). "Sensor Requirements for Future Building Control and Energy llanagement," Energy Conservation in Buildings through Improved Controls, ERDA Conference, Boston, MA.

Johnson, G. R. and C. B. Winn, 1975 (June). "Smart Thermostats for Minim-

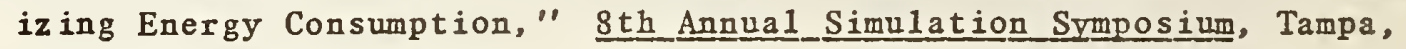
Florida, (received award).

Jones, J. W., J. R. Adams and T. N. Carnes, 1976 (Nay). "Improved Operation and Control Can Conserve Energy in an Existing office Building: A Case Study," Energy Conservation in Buildings Through Improved Controls, ERDA Conference, Boston, MA.

Kal hammer, F. R., 1979 (December). "Energy-Storage Systems," Scientific American, Vo1. 241, No. 6 .

Karaki, S. and P. R. Armstrong, 1978. "Air Conditioning by Nocturnal Evaporative Cooling of a Pebble Bed," DOE E-11-1-2868, Solar Energy Applications Laboratory, Fort Collins, Co.

Kent, T. B., 1978. "Control Applications and Limitations," Proceedings, First Workshop on the Control of Solar Energy Systems for Heating and 
Cooling, Eyannis, Mass., Published by the American Section of the International Solar Energy Society, Newark, Delaware, 202-205.

Kent, T. B., M. J. McGavin and L. Lantz, 1978. "Development of a Novel Controller," Proceedings of the First Workshop on the Control of Solar Energy Systems for Heating and Cooling. Published by the American Section of the International Solar Energy Society, Newark, Delaware.

Kilma, J., 1978. The Solar Controls Book, Solar Training Publication, Lakewood, CO.

Kovarik, M. and P. F. Lesse, 1976. "Optimal Control of Flow in Low Temperature Solar Heat Collectors," Solar Energy 18, 431-435.

Lewis, R., Jr. and J. B. Carr, 1978. "Comparative Study of On/Off Proportionally Controlled Systems," Proceedings of the First Horkshop on the Control of Solar Energy Systems for Heating and Cooling, AS/ISES Publishing Office, University of Delaware, Newark, Delaware.

Logan, J. L., 1980 (August). "A Control Scheme for Solar Industrial Process Steam Used for Potato Frying," Proceedings 1980 Joint Automatic Control Conference, San Francisco, CA.

Lorsch, H. G., R. L. Oswald and R. E. Crane, 1978. "Control Strategies for Electrical Peak Shaving," Proceedings of the First Workshop on the Control of Solar Energy Systems for Heating and Cooling, AS/ISES Publishing Office, University of Delaware, Newark, Delarare.

Lorsch, H. G., 1980. Nove1 Control Systems for Solar Systems that Reduce Electric Utility Peak Loads, Franklin Research Center, F-C4827, Philadelphia.

Lunde, P. J., 1982 a (March). "More One-Time for Solar Collectors," Solar Agge, Vol. 7, No. 3

Lunde, P. J., 1982b (Apri1). "Control of Active Systems Using the Stagnation Temperature," Solar Age, Vol. 7, No. 4.

McDonald, T. E., D. R. Farris and J. L. Melsa, 1978. "Energy Conservation through Adaptive Optimal Control for a Solar Heated and Cooled Building," Proc. First Workshop on the Control of Sola = Energy Systems for I Heating and Cooling. Hyannis, Mass., Published by the American Section of the International Solar Energ. Society, Newark, Delaware, 167-174.

McNal1, P.E., Jr., 1976 (May). "A Control Manufacturer's View of Research and Development Needs for Energy Conservation," Energy Conservation in Buildings Through Improved Controls, ERDA Conference, Boston, MA.

McNal1, P. E., Jr., and S. Buchannan, 1976 (May). "Research and Dovelopment Opportunities for Final Control Elements and Commuication Systems in HVAC Control Systems," Energy Consorvation in Bulldings Through Improved Controls, ERDA, Boston, MA. 
Moe, M. L., 1978. "Load Management for Solar Systems," Proceedings of the First Workshop on the Control of Solar Energy Systems for Heating and Cooling, AS/ISES Publishing Office, University of Delaware, Newark, Delaware.

Hoen, R. L. and R. D. Lane, 1978. "Solar Energy Management System (SEMS)," Proceedings of the First Workshop on the Control of Solar Energy Systems for Heating and Cooling, AS/ISES Publishing Office, University of Delaware, Newark, Delaware.

Mrnka, M. L., 1976 (May). "Controllers and Processor Applications," Energy Conservation in Buildings Through Improved Controls, ERDA Conference, Boston, MA.

Orbach, A., R. Fisch1 and P. R. Herczfeld, 1978. "An Improved Integration Method for Solar System Control Modeling Using the TRNSYS Program," Proceedings of the First Horkshop on the Control of Solar Energy Systems for Heating and Cooling, AS/ISES Publishing Office, University of Delaware, Newark, Delaware.

Orbach, A., C. Rorres and R. Fisch1, 1981. "Optimal Control of a Solar Collector Loop Using a Distributed-Lumped Hode1," Automatica 17. 535-539.

Piessens, L. P., Y. A. Beckman and J. W. Mitche11, 1981. "A TRNSYS Microprocessor Controller," Solar Engineering-1981: Proceedings ASME Solar Energy Division Third Annual Conference on SSEA and Operationa1 Results, Reno, NV.

Pryor, D. V., P. J. Burns and C. B. Winn, 1980, (August). "Parameter Estimation in Solar Structures by the Method of Least Squares," Proc. of the Joint Automatic Controls Conf., San Francisco.

Pryor, D. V. and C. B. Winn, 1982. "A Sequential Filter for Parameter Estimation in a Passive Solar System," Solar Energy, V28, p. 65.

Kiege1, X., Editor, 1976. Proceedings of the ERDA Conference: Technical Opportunities for Energy Conservation in Buildings Through Improved Contro1s, Boston, MA.

Rink, R, E, and H, Q. Le, 1981 (June). "Multivariable Feedback Control of Bilinear Processes in HVAC Systems," Proc. 24th Midwest Circuits and Systems Conference, Albuquerque, New Mexico.

Roots, W. K., 1969. Fundamentals of Temperature Contro1, Academic Press, New York and London.

Schiller, S. R., M. L. Warren and D. M. Auslander, 1980 (November). "Comparison or Proportional and On/Off Solar Collector Loop Control Strategies Using a Dynamic Collector hode1," Journal of Solar Energy Engineering, V. 102 , No. 4 .

Schindwolf, R., 1981 (August). "Fluid Temperature Control for Parabolic Trough Solar Collectors," Proceedings 1980 Joint Automatic Control 
Conference, San Francisco, CA.

Schindwolf, R., 1981 ( $\mathrm{Ju} 1 \mathrm{y}$ ). "Frequency Response Analysis of Fluid Control Systems for Parabolic-Trough Solar Collectors." SAND80-0385. Albuquerque, NM: Sandia National Laboratories.

Seba1d, A. V., et. a1., 1980. Impact of Controls in Passive Solar Heating and Cooling of Buildings, Final Report U. S. DCE DE AC04-79AL10891, Energy Center, UCSD, La Jo11a, CA.

Shih, J. Y., 1976 (May). "Control Systems and Principles," Energy Conservation in Buildings through Improved Controls, ERDA Conference, Boston, MA.

Shinsky, F. G., 1974. Energy Conservation Through Control, Academic Press, New York.

Sinha, A. K. and J. P. Sharma, 1975. "An On Line Technique for Weather Forecasting," Internationa 1 Journal of Systems Science, Vo1. 6, No. 7.

Solar Environmental Engineering Company, 1981 (October). Controllers for Solar Domestic Hot Hater Systems, SERI/TR-98189-1A, Golden, CO.

Somasundaram, M., J. L. Helsa and D. R. Farris, 1978. "Optima1 Contro1 Studies of a Solar Heating Systeri," Los Alamos National Laboratory, LA-UR 78-2556.

Soot, P. M., W. R. Go1dbach and C.B. Winn, 1975 (August). "New Dimensions in Water Heating in the Northwest-A Study of Solar Energy Utilization," IECEC, De1aware.

Su, W. S., and J. N. Castle, 1979, (Ju1y). State of the Art of Solar Contro1 Systems in Industrial Process Heat App1ications. SERI/TP-39240. Golden, C0: Solar Energy Research Institute.

Tierstein, L. M., 1975, (December). "Selecting Temperature Regulators and Controllers," Instrumentation Technology, pp. 52-59.

Vanderwei1, G., 1976 (May). "A Control Manufacturer's View of R D Needs for Energy Conservation," Energy Conservation in Buildings through Improved Controls, ERDA Conference, Boston, MA.

Winn, C. B., G. R. Johnson and J. B. Noore, 1974 (August). "Optimal Utilization or Solar Energy in tho Heatiug and Cooling of Buildings," International Solar Energy Society Annual beting, Fort Collins, Colorado.

Winn, C. B. and D. E. Hu11, 1976 (May). "Optimal Temperature Control for Structures," Energy Conservation in Buildings through Improved Contro1s, ERDA Conference, Boston, MA.

Winn, C. B. and N. Duong, 1977 (October). "Control Optimization for Peak Load Reduction in Heating and Cooling of Residential Solar Housos," Lawrence Symposium on Systems and Decision Science, Berkeley, CA. 
Fïinn, C. B. and D. Hul1, 1977 (December). "Optimal Temperature Control Using a Microprocessor," IEEE Decision and Control Conference, New Orleans, LA.

Winn, C. B. and N. Duong, 1978. "An Optimal Control Strategy for Peak Load Reduction Applied to Solar Structures," Proceedings of the First Workshop on the Control of Solar Energy Systems for Heating and Cooling, As/ISES Publishing Office, University of Delaware, Newark, Delaware.

Winn, C. B. and D. E. Hu11, 1979 (January). "Singular Optimal Control of Solar Space Heating Systems," Proc. 1978 IEEE Conf. on Decision and Control, San Diego, California, 1220-1224.

hinn, C. B. and K. Robinson, 1979 (December). "Optimal Control of an off Peak Storage Device in an Active Solar System," IEEE Conference on Decision and Control, Fort Lauderdale, FL. (invited paper).

Winn, R. C. and C. B. Winn, 1981. "Optimal Control of Mass Flow Rates in Flat Plate Solar Collectors," Journal of Solar Energy Engineering (ASME), V. 103, No. 4 .

Winn, C. B., R. C. Winn, C. A. Baer and P. R. Armstrong, 1982 (June). "Preferred Systems Controls for Optimizing the Performance of Solar Heating and Cooling and Heat and Cool Storage Installations," EPRI 1670-1, Falo Alto, CA.

Winn, C. B. and R. C. Winn, 1982, (June). "Optimal Control of Passive Solar Buildings with Load Managed Storage," Proc. 1981 AS/ISES Annual Meeting, University of Delaware, Newark.

Winn, C. B., 1982. Controls in Solar Energy Systems, American Solar Energy Society Publishing Office, University of Delaware, Newark.

Wright, J. D., 1980 (August). "Analytical Modeling of Line Focus Solar Collectors," Proceedings 1980 Joint Automatic Control Conference, San Francisco, CA. 
NBS.114A IREV. 2-8C)

U.S. DEPT. OF COMM.

. PUBLICATION OR

2. Performing Organ. Report Nof 3. Publication Date

BIBLIOGRAPHIC DATA REPORT NO.

SHEET (See instructions)

NBSIR 84-2980

December 1984

4. TITLE AND SUBTITLE

RESEARCH PRIORITIES FOR IMPROVING THE EFFECTIVENESS OF ACTIVE SOLAR HOT WATER AND SPACE CONDITIONING SYSTEMS

5. $\operatorname{AUTHOR}(\mathrm{S})$

Robert D. Dikkers, William J. Kennish, C. Byron Winn, William Huston

6. PERFORMING ORGANIZATION (If joint or other than NBS, see instructions)

NATIONAL BUREAU OF STANDARDS

DEPARTMENT OF COMMERCE

WASHINGTON, D.C. 20234

9. SPONSORING ORGANIZATION NAME AND COMPLETE ADDRESS (Street, City, Stote, ZIP)

7. Contract Grant No.

DE-AI01-76PR06010

8. Type of Report \& Period Covered

Fina1

U. S. Department of Energy

office of Solar Heat Technologies

Active Heating and Cooling Division

Washington, DC 20585

10. SUPPLEMENTARY NOTES

Document describes a computer program; SF-185, FIPS Software Summary, is attached.

11. ABSTRACT (A 200-word or less factuol summory of most significant information. If document includes a significant bibliogrophy or literature survey. mention it here)

As part of the FY 1983 Department of Energy Systems Effectiveness Research Program, the National Bureau of Standards (NBS) was assigned responsibility for developing research priorities for improving the effectiveness (i.e., thermal performance, cost, reliability and maintainability) of active solar hot water and space conditioning systems. To carry out this task, NBS, in cooperation with various industry representatives, organized and conducted two meetings in August $1283 . \quad$ The $\mathrm{f} 1 \mathrm{rst}$ meeting covered al1 major aspects of active solar hot water and space conditioning systems. The second meeting dealt only with solar control subsystems. Based on information obtained from these meetings, recommended research priorities for improving the effectiveness of active solar energy systems are presented.

12. KEY WORDS (Six to twelve entries; alphabetical order; capitalize only proper names: and seporote key words by semicolons) Control subsystems; materials; reliability; research priorities; solar heat1ng; solar hot water; test and evaluation procedures; thermal performance

13. AVAILABILITY

$\mathrm{x}$ Unlimited

For Official Distribution. Do Not Release to NTIS

Order From Superintendent of Documents, U.S. Government Printing Office, Washington, D.C. 20402.

[x] Order From National Technical Information Service (NTIS), Springfield, VA. 2216I
14. NO. OF

PRINTEO PAGES

75

15. Price

$\$ 10.00$ 


